\title{
LA TRANSFERENCIA DE LA PROPIEDAD EN LA COMPRAVENTA DE BIENES MUEBLES EN EL DERECHO PRIVADO EUROPEO (DCFR Y CESL)
}

Jakob Fortunat Stagl

Universidad Bernardo O'Higgins

Universidad de Chile

"La ciencia jurídica debería pertenecer también a los reyes constructores y no sólo a las personas de esfuerzo"

Rolf Stürner ${ }^{1}$

\section{LA UNIFICACIÓN DE LAS REGLAS SOBRE TRANSFERENCIA}

DE LA PROPIEDAD EN LA COMPRAVENTA

\section{DCFR y CESL como etapas de la unificación jurídica}

Con el DCFR, se pone ante nuestros ojos el proyecto de un código civil europeo $^{2}$ que, en línea con lo que se esperaría, regula tanto la compraventa como la transferencia de la propie$\mathrm{dad}^{3}$. Dado que por razones políticas

1 "Die Rechtswissenschaft sollte auch zu den bauenden Königen gehören und nicht nur zu den Kärrnern”, STÜRNER (2014), pp. 7, 41.

${ }^{2} \mathrm{Al}$ respecto, véase Doralt (2011), p. 1; Eidenmüller, Faust, Grigoleit, Jansen, WaGNER Y ZIMMERMANN (2008), p. 529; ERNST (2008), p. 248; ZimMERMANN y JANSEN (2009), p. 3401. Sobre el trabajo del Study Group on a European Civil Code y del Acquis Group, véase LuRger (2008), p. 1.

${ }^{3}$ Lurger y Faber (2011). Principles of European Law - Acquisition and Loss of Ownership of Goods. Se trata de una versión amplia y profundizada de Principles, Definitions and Model Rules of European Private Law - Draft Common Frame of Reference (Full Edition), editado por vON BAR y Clive (2009). no será posible darle fuerza de ley a este proyecto de codificación, sirve como acervo de futuras normas en el ámbito europeo ${ }^{4}$. La rapidez con la que el legislador europeo se serviría de esas normas que tiene a disposición, queda demostrada en la propuesta relativa a una "normativa común de compraventa europea" ${ }^{5}$ (CESL) ${ }^{6}$, un derecho uniforme opcional para los contratos de compraventa transfronterizos. (En este momento no tiene fuerza de ley debido a que la normativa fue retirada en 2014, sin embargo, la Comisión Europea propondrá una nueva normativa, muy semejante, que tratará de forma más intensa el comercio electrónico $\left.{ }^{7}\right)$. A diferencia del DCFR, el CESL no contiene ninguna regla expresa sobre transferencia de la propiedad en la compraventa, sino que más bien deja el asunto al Derecho Internacional Privado de los Estados

${ }^{4}$ La formulación es de Rabel (2008), pp. 248, 277.

${ }^{5}$ PR CESL, COM (2011), p. 635 final. Al respecto, véase Eidenmüller, Jansen, Kieninger, Wagner y Zimmermann (2012), p. 269 y RÜFNER (2012), p. 476.

${ }^{6}$ Véase Eidenmüller, Jansen, Kieninger, WAgner y Zimmermann (2012), p. 269, n. 2.

${ }^{7}$ ChIVe (2014) y véase también el European Law Institute (2014). 
miembros ${ }^{8}$, siguiendo a su modelo, la CISG $^{9}$. Ernst Rabel, el "cerebro" de la Convención de Viena ${ }^{10}$, justificó esta elección de técnica legislativa en razón de que los aspectos del contrato de compraventa que pertenecen al Derecho de los Bienes son de gran relevancia desde el punto de vista teórico, pero de modesta importancia en la práctica ${ }^{11}$.

El DCFR es un proyecto para la unificación de los derechos de los Estados miembros: las codificaciones nacionales deberían ser sustituidas en último término por una codificación europea de Derecho Privado ${ }^{12}$. En el caso del CESL esto solo es indirectamente cierto. Sin embargo, es correcto comprenderlo también como un vehículo de la unificación jurídica: por un lado, sus disposiciones provienen en gran medida de la regulación de la compraventa contenida en el DCFR ${ }^{13}$ $y$, por otro, un objetivo declarado del Derecho Uniforme es incentivar la reforma de los ordenamientos nacionales ${ }^{14}$.

${ }^{8}$ Considerando $\mathrm{N}^{\mathrm{o}} 27$ del PR CESL; LORENZ (2012), pp. 702, 713, 723.

${ }^{9}$ Art. 4 , inc. $2^{\circ}$, letra (b) de la CISG; véase sobre el punto a Franco Ferrari en SCHLECHTRIEM y SCHWENZER (2013), art. 4, parágrafo 29 y ss.

${ }^{10}$ Schlechtriem y Schroeter (2013), parágrafo 2; sobre el papel de Ernst Rabel en el desarrollo del derecho de la CISG, véase STAGL (2011), p. 433, con referencias adicionales.

${ }^{11}$ Rabel (1936), p. 31 y ss.

${ }^{12}$ VON BAR y SCHULTE-NÖLKe (2009), p. 61 y ss.

${ }^{13}$ Sobre "escalones textuales" (Textstufen) del Derecho Privado europeo, véase EIDENmÜller, Jansen, Kieninger, Wagner y ZimMERMANN (2012), pp. 269-270 y ss.

${ }^{14}$ Así Rabel (1936), p. 35, con referencia al futuro Derecho Internacional Uniforme de la Compraventa.

Si se quiere unificar el derecho en un determinado asunto, hay dos posibilidades $^{15}$ : se puede declarar por lo general aplicable una de las soluciones existentes o, bien, crear una solución completamente nueva ${ }^{16}$. En la cuestión que nos ocupa puede excluirse la segunda opción, desde que no puede esperarse que la perspicacia jurídica de nuestro tiempo sea capaz de inventar algo nuevo en este ámbito ${ }^{17}$. Se trata, entonces, de seleccionar entre las soluciones disponibles, preguntando por las razones para tomar y justificar una decisión ${ }^{18}$. Ernst Rabel fue uno de los pocos que se pronunció sobre esto: teniendo en cuenta las exigencias del comercio, la elección debía realizarse considerando "reglas fundamentales" comunes, identificadas mediante la comparación ${ }^{19}$. Pero, ¿̇existen en Europa reglas fundamentales comunes sobre la transferencia de la propiedad en la compraventa?

${ }^{15}$ Es fundamental al respecto Blaurock (1992), p. 90 y ss.; CoIng (1974), p. 7 y ss.

${ }^{16}$ LURger y FABER (2011), p. 209, donde, a partir de estas premisas, se extrae la conclusión opuesta.

${ }^{17} \mathrm{Al}$ respecto, véase MaYer-MaLY (1971), p. 1.

${ }^{18}$ Para este propósito, véase también $\mathrm{FA}_{\mathrm{A}}$ BER, LILJA y KReUZbauer (2012), pp. 10 y ss., 232 y ss. La teoría de la argumentación es una forma de retórica y no, por sí misma, un método científico. La retórica es propicia para la ciencia solo indirectamente, por la necesidad de réplica, pero no por su propia intención: Stagl (2014), p. 862; Stagl (2013), p. 2.

${ }^{19} \operatorname{Rabel}$ (1957), p. $117=\operatorname{RABEL}$ (1967), pp. 477, 481; en el mismo sentido KROPHOLLER (1975), p. 254 y ss. y GuZMán BRITo (1977), p. 21 y ss. 


\section{El variado acervo de la tradición jurídica europea como obstáculo para la unificación}

a) El realismo jurídico escandinavo

El cuadro de la transferencia de la propiedad en Europa muestra contrastes extremos: existe, en primer lugar, la escuela escandinava del realismo jurídico, que, con un argumento interesante, niega de raíz que exista una 'propiedad' y que esta pueda 'transferirse ${ }^{20}$. Esta escuela no se pregunta, como se hace de forma habitual, quién es propietario, para poder extraer de ahí las consecuencias jurídicas ${ }^{21}$, más bien observa, desde el punto de vista de las funciones que cumple, cada relación jurídica que deriva de lo que podría llamarse 'propiedad'22. Si por tradición se extrae, por ejemplo, la facultad de goce de la cosa vendida de la propiedad, los escandinavos evitaban esta inversión y se preguntaban si el vendedor de una cosa puede gozar cuando el comprador ya pagó, pero todavía no ha recibido materialmente la cosa objeto de la compraventa ${ }^{23}$. Este modo de proceder es intelectualmente honesto, en cuanto representa una transposición consecuente, en la ciencia del Derecho, del nominalismo de la Filosofía, pero es inservible en la práctica. Es más, complica el trabajo del jurista y, por esto, lo hace susceptible de errores: ¿ cómo se puede establecer a quién corresponde

${ }^{20}$ En el mismo sentido, véase HÅsTAD (2009), pp. 725-726 y ss., también MarTinson (2008), p. 69 y ss.

${ }^{21}$ HÅstad (2009), pp. 725-726.

${ }^{22}$ Bjarup (1978), p. 165 y ss.

${ }^{23}$ HÅsTAD (2009), pp. 725-726. la facultad de goce si no se la extrae de la propiedad o de la autonomía privada? ${ }^{24}$ A partir de una evaluación de los intereses de las partes, es la respuesta de esta escuela. El enfoque funcional intercambia, entonces, una idea por otra: la propiedad por el interés. Decidir conflictos de interés es, sin embargo, tarea primaria de la política. Esta escuela sustituye el concepto metafísico de propiedad por la ideología ${ }^{25}$, lo que no se condice con la ciencia del Derecho, que es, en cambio, en su más íntima esencia, una ciencia emanada del principio de igualdad, al que queda vinculado ${ }^{26} \mathrm{y}$, por tanto, necesariamente una ciencia formal ${ }^{27}$.

b) Los tres sistemas clásicos

En el resto de Europa, de orientación esencialista, se desarrollaron, desde el Derecho Romano, principalmente tres sistemas ${ }^{28}$ de transferencia de la propiedad mueble ${ }^{29}$ : según el principio del consensualismo o principio de unidad, que rige en el Code Civil de $1804^{30}$ y en los demás códigos inspira-

${ }^{24}$ VAN Vliet (2011), pp. 292, 294.

${ }^{25}$ La misma crítica se encuentra en FABER (2008), p. 97.

${ }^{26}$ RAdBRUCH (1993) p. 258; STÜRNER (2014), p. 11, con referencias adicionales.

${ }^{27}$ Schiavone (2005), p. 390 y ss. Con particular referencia al Derecho Comunitario, véase también a MARTENS (2013), p. 414, con referencias adicionales; RöHL (2013), parágrafo 11.

${ }^{28}$ Esta tripartición es utilizada, por ejemplo, por Caemmerer (1938/39), p. 675 y ss.; KASER (1962), p. 28 y ss.; RABEL (1936), p. 27 y ss.; Von Bar y Drobnig (2004), p. 325 y ss. A ella se refiere también, con algunas variaciones, LURGER y FABER (2011), p. 466 y ss.

${ }^{29}$ Zwalve y Sirks (2012), p. 267 y ss.

${ }^{30}$ Para una ilustración completa, véase RANIERI (2009), pp. 7 y s. y 1075 y ss. 
dos en é $\mathrm{l}^{31}$, la propiedad sobre la cosa objeto de la compraventa se transfiere al comprador con la sola celebración del contrato de compraventa, aunque la cosa no se haya entregado o pagado, como expresamente dispone la regla crucial al respecto ${ }^{32}$. De esta manera, el $C C$ no establece una separación entre negocio causal y acuerdo real, sino que, más bien, dota al propio contrato de compraventa de un effet translatif (efecto traslaticio $)^{33}$.

El contraste más directo con el Code Civil lo ofrece el $B G B$ de 1900. Según el $B G B$, el contrato de compraventa no tiene relevancia alguna para la transferencia de la propiedad, tampoco la tiene su validez. Solo es necesario que las partes estén de acuerdo con que el dominio debe pasar del vendedor al comprador ${ }^{34}$.

${ }^{31}$ Por ejemplo, en Italia (arts. 922, 1376 ss. del Codice Civile): $\mathrm{Al}$ parecer, en determinados ámbitos la teoría del titulus y del modus reclama validez paralela, y en otros, incluso, rige el principio de abstracción; al respecto, véase $\mathrm{ZA}_{\mathrm{A}}$ CCARIA (2009), Art. 1376 parágrafo 1 y ss.; en Bélgica (arts. 711, 938, 1138, 1583 del Code Civil); en Portugal (arts. 408 y s., 874, 879, 1316 en Código Civil). También Sales of Goods Act inglés (parágrafos 16 a 26) está fuertemente influenciado por el Code Civil: en Inglaterra la situación es muy complicada por la coexistencia del Common Law y el Sales of Goods Act. BRIDGE (1997), p. 61 y ss.; Goode (2004), p. 207 y ss.; VAN Vliet (2000), p. 91 y ss.; Zwalve y Sirks (2012), p. 311 y ss.; HäcKer (2011), p. 335.

${ }^{32}$ Art. 1583; véanse también los arts. 1138 y 711 del Code civil.

${ }^{33}$ Atias (2009), p. 201 y ss.; Terré y Simler (2010), p. 317 y ss.; Saint-Alary Houin (1991), p. 197 y ss.; Ferid y Sonnenberger (1986), p. 201 y ss.; VAN Vliet (2000), p. 73 y ss.

${ }^{34} \mathrm{Al}$ respecto, véase a Christian Berger en JaUernig (2014), § 854 parágrafo 13. Sobre el principio de abstracción, consúltese la obra fundamental de Von SAVIGnY (1840), vol. III, p. 356 y ss. (hay varias traducciones al español
Desde este punto de vista, el contrato de compraventa se convierte simplemente en el motivo de la transferencia de la propiedad realizada por medio de un acuerdo real y el traspaso efectivo de la posesión (traditio), que tiene como efecto la transferencia de la propiedad. En otras palabras, en la lógica del $B G B$ hay tres actos lógicamente distintos: un contrato de compraventa, un acuerdo real de transferencia (dinglicher Vertrag) y una tradición entendida como un hecho consistente en la entrega material de la cosa. Visto que el $B G B$ pone muy bajas exigencias al principio de la tradición y admite tantas excepciones -en especial, el constituto posesorio (§930 del BGB)- Philipp Heck está en condiciones de afirmar que este principio sería solo el "ropaje histórico" en que la transferencia de la propiedad puramente consensual habría encontrado su entrada en el Derecho vigente ${ }^{35}$. En efecto, el constituto posesorio consiste en una transferencia de la propiedad puramente consensual, en que el enajenante pierde la propiedad sin que medie una entrega. El Derecho alemán distingue, entonces, entre la obligación a transferir la propiedad, propia del Derecho de las Obligaciones, y la transferencia misma de la propiedad, entendida como negocio jurídico en sí mismo (principio de separación, Trennungsprinzip) llamado

como "Sistema de Derecho Romano actual", una de las más recientes de José Luis, Moreno, en Editorial Albolote, Granada: Comares, 2005); Von SaVigny (1853), p. 254 y ss.; EhmanN (2010), pp. 1, 4 y ss.; RANIERI (2009), p. 1056 y ss.; Huber (2007), p. 471 y ss.; Zwalve y Sirks (2012), p. 351 y ss.; STADLER (1996), p. 76 y ss. ${ }^{35}$ Heck (1930), p. 241. 
dinglicher Vertrag (acuerdo real). Puesto que la validez del acuerdo real de transferencia no depende de la validez del contrato de compraventa que le antecede, se dice que el acuerdo real de transferencia se abstrae del contrato de compraventa previo (principio de abstracción, Abstraktionsprinzip).

Por cuanto sabemos, en la actualidad en Europa tal vez solo Grecia conoce un régimen de transferencia de la propiedad comparable al alemán ${ }^{36}$; en el Derecho escocés la cuestión, a falta de una opinión unívoca, es muy controvertida, aunque la tendencia va en dirección de la abstracción ${ }^{37}$. Fuera de Europa el principio de abstracción se ha afirmado, por ejemplo, en el Derecho Romano-holandés de Sudáfrica ${ }^{38}$ y en Taiwán.

La solución intermedia entre los dos extremos la ofrece la tercera teoría, la que distingue entre titulus y modus ${ }^{39}$, que sigue, por ejemplo, el Derecho austríaco, suizo ${ }^{40}$, el de los Países Bajos y también el Derecho español ${ }^{41}$. Según esta teoría, la transferencia de la propiedad depende de que exista un con-

${ }^{36} \mathrm{El}$ art. 1034 dell' Astikos Kodikas corresponde al $\S 929$, inc. $1^{\circ}$ del $B G B$; para las referencias, véase ScHLECHTRIEM (2000), p. 288.

${ }^{37}$ Carey Miller (1991), § 8.06 y ss., con numerosas referencias adicionales; REID (1996), $\S 608$.

${ }^{38}$ Carey Miller (1996), pp. 727, 734 ss., con ulteriores referencias; ZIMMERMANN (1990), p. 271.

${ }^{39}$ Sobre esta teoría, véase CoING (1985), pp. 178 y s., 302 y ss.; Hofmann (1873), p. 1 y ss.; RANIERI (2009), p. 1051 y ss.

${ }^{40}$ Ranieri (2009), p. 1069 y ss.

${ }^{41}$ Art. 609. Código civil español. El pacto de la reserva del dominio no está regulado, aunque generalmente aceptado. Véase MARÍN CASTÁN, en Sierra Gil de la Cuesta (2000), pp. 7 s. trato de compraventa válido, o sea, un título traslaticio (titulus), y que la cosa sea entregada (modus). En cuanto al modus se admiten algunas excepciones: en particular, el constituto posesorio, en el que el traspaso de la posesión se desmaterializa completamente. Según la concepción original, el modus debía entenderse como un mero acto físico de entrega, no se presuponía, entonces, la existencia de un acuerdo jurídico real dirigido a la transferencia de la propiedad $^{42}$. Posterior a la influencia de la doctrina alemana, en Austria, como también en los países mencionados, se admitió un acuerdo real de transferencia similar ${ }^{43}$. La validez de este acuerdo real de transferencia aún no se abstrae de la validez del contrato de compraventa, sino que permanece vinculada a esta. El contrato de compraventa se mantiene como la causa del acuerdo real de transferencia; por esa razón se habla del "principio de causalidad".

La recepción del acuerdo real se explica, sobre todo, porque su adopción hace posible construir, de manera plausible, la cláusula de reserva del dominio en la compraventa: las partes pueden obligarse de manera inmediata, haciendo depender la transferencia de la propiedad del pago del precio de la compraventa. Por el contrario, la

${ }^{42}$ GLÜCK (1807), p. 89 y ss.; al respecto, véase también RANIERI (1977), p. 90 y s.

${ }^{43}$ Países Bajos (art. 3:84 Burgerlijk Wetboek): RANK-BERENSCHOT (2011), art. 3:83 parágrafo 1 y ss.; VAN Vliet (2000), p. 133 y ss., n. 29; Austria (§§ 380, 423 yss. $A B G B$ ): fundamental, para la doctrina más reciente, BYDLINSKI (1978), p. 370 y ss.; SpIElbÜCHLER (2000), § 425 parágrafo 2; Suiza (art. $714 Z G B$ ): hay jurisprudencia constante a partir del BGer 29. 11. 1929, BGE 55 II 302; SCHWANDER (2011), art. 714 parágrafo 5; ERNST (2010), p. 75. 
doctrina francesa, a falta de acto jurídico real -al menos podemos asumir que es esa la razón- no ha logrado hasta ahora construir de modo convincente una explicación fuerte para la validez de cláusula reserva del dominio ${ }^{44}$.

\section{c) La naturaleza científica del problema}

La cuestión relativa a la transferencia de la propiedad en la compraventa se sitúa en el límite entre el Derecho de las Obligaciones y el Derecho de los Bienes $^{45} \mathrm{y}$, según el lado al que más se acerque, son completamente diferentes las construcciones jurídicas que derivan. No es posible, entonces ${ }^{46}$, partir de la base que existen reglas comunes, es decir, una tradición europea susceptible de unificación ${ }^{47}$. Por lo tanto, no es posible aspirar a una evolución orgánica de las tradiciones existentes. La tesis de Franco Ferrari ${ }^{48}$, que sostiene lo contrario, se funda en la praesumptio similitudinis $^{49}$ : según la tesis dominante, es cierto que en Europa el asunto se regula mediante sistemas muy diferentes, pero las diferencias estarían no tanto en las soluciones concretas sino en la

\footnotetext{
${ }^{44}$ Saint-Alary Houin (1991), pp. 197, 206 y ss.

${ }^{45}$ Kaser (1962), p. 7.

${ }^{46}$ Lo señala también Giaro (1994), p. 19. Se muestra escéptico también Forschner (2012), p. 6.

${ }^{47}$ Respecto a la pregunta si esa forma de proceder es siquiera metodológicamente admisible, se encuentran posturas favorables, por ejemplo, ZimMERMANN (2001), p. 244, y otra desfavorable, contraria, seguida, en este caso, por GIARO (1994), p. 1, como también una tentativa de mediación, que se debe a Picker (2001), p. 763.

${ }^{48}$ Ferrari (1993), p. 52 y ss.

${ }^{49} \mathrm{Al}$ respecto, véase Michaels (2006), pp. 339-382.
}

construcción técnico-jurídica ${ }^{50}$. Pero la construcción técnico-jurídica es justamente el factor crucial de la transferencia de la propiedad en la compraventa. Recurriendo a una metáfora visual, la transferencia de la propiedad es similar a la pieza clave del arco de una bóveda: su forma debe responder a la arquitectura de la bóveda en su totalidad, y si la clave del arco no es la adecuada, falla la estática de toda la construcción.

En la cuestión de la transferencia de la propiedad, que parece tener relevancia meramente teórica, se expresa la especificidad de las distintas codificaciones: el asunto no sorprende, desde que el Derecho consiste justamente, como decía Ulpiano, "en adquirir, en conservar o en disminuir" $\operatorname{cosas}^{51}$. Entonces, respecto al asunto específico del traspaso de la propiedad en la compraventa, nos encontramos con un problema en que la teoría adquiere relevancia en el plano práctico porque es expresión de estructuras fundamentales que se contraponen: la piedra clave propia del Derecho francés no armoniza con en el Derecho alemán y viceversa, aunque ambas tengan la misma función práctica y sean, por tanto, muy similares vistas de lejos.

Para resolver este problema, es, entonces, pertinente elaborar un método diferente al propuesto por Ernst Rabel. Fieles a una enseñanza fundamental de la Escuela Histórica de Derecho (Historische Rechtsschule), es preciso partir, en una primera fase, de la premisa que en el Derecho se pueden distinguir

${ }^{50}$ Von Bar y Drobnig (2004), p. 327 y ss.; Von Caemmerer (1938/1939), pp. 675, 682, 697; VAN Vliet (2000), p. 201.

${ }^{51}$ Digesto 1, 3, 41 (Ulpiano). 
los asuntos de naturaleza científica de los de naturaleza política ${ }^{52}$ y que los problemas relativos a la transferencia de la propiedad en la compraventa son, sobre todo, de naturaleza científica: para mantener nuestra imagen, se trata de calcular la forma adecuada de la clave del arco sobre la base de la arquitectura del resto de la codificación. Entonces, si delante de nosotros tenemos un problema científico-y no un problema político- se exige resolverlos con métodos científicos.

El significado de 'científico' puede ser ilustrado recurriendo a su contrario: se podría decir que el principio del consensualismo privilegia a los acreedores del comprador, en cuanto hace que la propiedad pase a este lo antes posible; el Derecho alemán y el austríaco privilegiarían, por el contrario, a los acreedores del vendedor, porque le entregarían a él la elección de transferir la propiedad y así también la posibilidad de postergar el traspaso de la propiedad ${ }^{53}$. Teniendo esta consideración a la vista, los redactores del DCFR fueron en búsqueda de las razones por las que se debería privilegiar específicamente a los acreedores del comprador o del vendedor. De este modo, las normas de transferencia de la propiedad de los bienes muebles debería servir para proteger los intereses merecedores de tutela $a^{54}$. Sin embargo, es imposible encontrar argumentos de ese tipo, porque los intereses del vendedor y del comprador, para usar la recho.
(1953-54), p. 145
${ }^{53}$ LURGer y Faber (2011), p. 415 y ss.
${ }^{54}$ Op. cit., p. 209; mejor enfoque del De-

expresión de Philipp Heck "se anulan mutuamente" 55 . Y lo hacen porque el contrato de compraventa es un bonae fidei iudicium $^{56}$, es decir, un negocio en el que reina la medida del aequitas ${ }^{57}$. Según este principio, es pertinente distribuir las ventajas y desventajas de modo de establecer un resultado equilibrado entre las partes ${ }^{58}$, el que no se podría conseguir si se privilegiara una de las partes por sobre la otra. Por lo tanto, no se debe favorecer a ninguna de las partes. Pero no solo la compraventa que se sustrae de tales favoritismos sino que los favoritismos mismos son sospechosos desde el punto de vista científico, porque, en realidad, se trata de juicios de valor ${ }^{59}$. $\mathrm{Y}$ a un juicio de valor se puede adherir o no. No existe, todavía, un método científico generalmente reconocido con el que se pueda convencer a otros que deban formular un mismo juicio de valor $^{60}$.

Así las cosas, veamos qué posibilidades existen para darle a la transferencia de la propiedad en la compraventa una solución que no se base en un juicio de valor y que sea, por tanto, científica.

${ }^{55}$ Heck (1930), p. 119; en sentido análogo Flume (1992), § 12 III 3; GRigoleit (1999), pp. 379, 382; ZimmermanN (1990), p. 272.

${ }^{56}$ Gaius, Institutiones 4, 62.

${ }^{57}$ KASER (1971), p. 487 y s. En este sentido, además, GuZMán Brito (1977).

${ }^{58}$ Stagl (2007), p. 675 y ss.

${ }^{59}$ Sobre el punto, véase a STAGL (2009), pp. 317 y ss. y 327 y ss.; STAGL (2014), pp. 129, 131 y ss.

${ }^{60}$ Con referencia a la ciencia jurídica, véase al respecto a CANARIS (1983), p. 40 y ss.; en general, WeBER (1904), p. 22 y ss., también (1922), p. 146 y ss. 


\section{Unificación jurídica de tradiciones diversas}

\begin{abstract}
a) Las "cuatro causas" aristotélicotomistas como método para individualizar la norma
\end{abstract}

La metodología de la ciencia jurídica sirve, no tanto para hacer leyes, sino, más bien, para interpretarlas ${ }^{61}$. En lo que nos interesa, se puede aplicar el método de interpretación de las leyes según el tenor literal, la historia, la sistemática y su sentido y finalidad ${ }^{62}$ : la interpretación misma es una forma de legislar ${ }^{63} \mathrm{y}$, además, el procedimiento hermenéutico no es más que una aplicación de las cuatro causas aristotélicas de juicio (gr. aitia = lat. causae) al problema de la interpretación. La doctrina dominante no considera este origen porque se limita a explorar la historia de la interpretación solo a partir de Friedrich Carl von Savigny ${ }^{64}$. Según Aristóteles ${ }^{65}$, solo podemos co-

${ }^{61}$ ERnst (2007), pp. 3, 27. La justificación de esta afirmación se encuentra en EssER (1972), pp. 3 , 7 y ss.

${ }^{62}$ Kramer (2013), p. 58 y ss.; LaRenz y CANARIS (2005), p. 141 y ss.; Huber (2003), pp. 1,5 y s.

${ }^{63}$ Kramer (2013), p. 183 y ss.

${ }^{64}$ Hasta ahora, este aspecto ha sido ignorado. El procedimiento hermenéutico no puede ser reconducido a la doctrina retórica de los status, a diferencia de lo que afirma, por ejemplo, SCHröder (2001), p. 57 y ss. La doctrina retórica de los status conoce, como "terrenos de enfrentamiento" (Kampflagen), verba/voluntas e leges contrariae, pero no contempla el factor histórico. La pregunta si existe una correlación genética, entre las causas aristotélicas y la doctrina de los status, sería una cuestión en sí. Sobre la doctrina de los status, es fundamental CAlBOLI Montefusco (1986); LAUSBERG (2008), §§ 79-138.

${ }^{65}$ Aristóteles, Metafísica, v, 2/1013a 241013b. nocer una cosa si conocemos sus causae, o sea, cuando sabemos por qué está hecha así como es ${ }^{66} . \mathrm{Al}$ respecto, se debe distinguir entre:

- Causa materialis: ¿de qué está hecha la cosa? Por ejemplo ${ }^{67}$, de bronce. Esto corresponde al tenor literal de la norma.

- Causa formalis: ¿cómo aparece la cosa, cómo se inserta en el ambiente que la rodea? Por ejemplo, la forma de una estatua, la postura de los brazos y de las piernas, etc. Esto corresponde al contexto sistemático de la norma.

- Causa efficiens: ¿quién o qué ha hecho la cosa? Praxíteles, por ejemplo. Esto corresponde a la interpretación histórica.

- Causa finalis: ¿Para qué fue hecha la cosa, cuál es su función o finalidad? ¿La estatua está destinada a un templo o a una villa? Esto corresponde a la interpretación teleológica.

A través de las reflexiones de Tomás de Aquino ${ }^{68}$, las cuatro causas se convirtieron en uno de los fundamentos de la filosofía occidental e hicieron su entrada en la ciencia jurídica, probablemente a través de la teología y escolástica española tardía ${ }^{69}$. Son

${ }^{66}$ Andrea Falcon en Stanford Encyclopedia of Philosophy, s.v. Aristotle on Causality (2006), disponible en http://plato.stanford.edu/entries/aristotle-causality/.

${ }^{67}$ Según HöFre (2008), p. 55, el ejemplo se debe, en parte, a Aristóteles.

${ }^{68}$ Tomás DE AQuino, De principiis naturae, 3, 20; Tomás DE AQUino, Summa Theologica $\mathrm{II}-2$ quaest. 27, art. 3; véase al respecto, la introducción de Feser (2009), p. 16 y ss. y PATt (2007), p. 150 y ss.

${ }^{69}$ Véanse los actos de la convención: La segunda escolástica en la formación del Dere- 
un instrumento universal de conocimiento, perfeccionado dentro la teoría moderna de argumentación jurídica ${ }^{70}$, y que en nuestro caso se aplicará a la legislación.

b) La primacía de los argumentos teleológico-sistemáticos

De lege ferenda los argumentos basados en el tenor literal solo tienen importancia ahí, donde, desde las partes ya vigentes de una codificación, se extraen conclusiones válidas para las aún ignoradas. Así, Lars van Vliet, en su análisis sobre la transferencia de la propiedad, extrae del término 'effective transfer' al que se refieren los materiales que acompañan el DCFR ${ }^{71}$ que los redactores tal vez habrían partido de la base que existe un acuerdo real, en cuanto un transfer, entendido en el sentido puramente factual, podría tener lugar o no, pero no podría ser eficaz o ineficaz ${ }^{72}$.

Como ya hemos señalado, lamentablemente no existe un régimen de transferencia de la propiedad en la compraventa que se haya desarrollado históricamente de manera orgánica, pero esto no impide recurrir a argumentos históricos en determinados contextos teleológico-sistemáticos. Junto a la estrategia conservadora, enfocada a legitimar el presente mirando al pasado, siempre ha existido el intento de revivir un pasado ya

cho Privado moderno, editado por Grossi (1973) y Seelmann (1997); sobre la teoría continental premoderna de la interpretación, GuzMÁN BRITO (2011), pp. 43-92.

${ }^{70}$ Para un panorama de Derecho Comparado, véase Henninger (2009), p. 379 y ss.

${ }^{71}$ LURGER y FABER (2011), pp. 435, 460, 463.

${ }^{72}$ VAN Vliet (2011), pp. 292, 299 y s. muerto $^{73}$. La única forma de hacer esto sería acudiendo al Derecho Romano clásico $^{74}$. Solo que, incluso, si se estuviera dispuesto a ello, no se escaparía del problema de la diversidad de sistemas de transferencia de la propiedad. En relación con este tema en particular, las fuentes del Derecho Romano son tan contradictorias y llenas de lagunas ${ }^{75}$ que los ordenamientos jurídicos europeos desarrollaron distintos sistemas de transferencia de propiedad, que se contraponen unos a otros, partiendo precisamente desde esas mismas fuentes $^{76}$. En consecuencia, ni en la ciencia romanística hay acuerdo sobre cuál es el derecho romano clásico en esta materia $^{77}$, y nuestra mirada sobre las fuentes romanas está marcada por una precomprensión ${ }^{78}$ que tiene su origen en nuestro propio ordenamiento nacional, el que, a su vez, es, irónicamente, una derivación del Derecho Romano.

No se debe confundir con la teleología los argumentos basados en los intereses, que antes calificamos como inservibles para nuestros propósitos. Es

${ }^{73}$ Crítico, al respecto, Zimmermann (2002), pp. 243, 312.

${ }^{74}$ SCHUlz (1951), p. 343 y ss.; KASER y KNÜTEl (2013), § 24; KunKel y MaYer-Maly (1987), p. 156 y ss.; entre las investigaciones especializadas más recientes se pueden mencionar: Kaser (1961), p. 61; Pugliese (1997), p. 25 y ss.

${ }^{75}$ Schulz (1951), p. 350.

${ }^{76}$ Sea también por vías transversales, gracias a la influencia del derecho vulgar y de los glosadores; KASER (1962), p. 42 y s.

${ }^{77}$ Con referencia al problema de iusta causa traditionis, ver por una parte: KASER (1961), p. 61; KunKel y Mayer-Maly (1987), p. 156; KASER y KNÜTEL (2013), § 25 parágrafo 11 y, por otra, JaKobs (2002), pp. 269, 304 y ss.; Schulz (1951), p. 350.

${ }^{78}$ Sobre los problemas de la hermenéutica jurídica, véase BETTI (1954), p. 79 y ss. 
especialmente relevante para el método teleológico el principio de la estricta igualdad entre las partes, que emerge de la naturaleza misma de la compraventa como negocio de intercambio. De esta igualdad se desprende la prohibición de tratamientos preferenciales, y de esta deriva también la conclusión, que se ilustrará más adelante, según la cual la propiedad debe transferirse junto con el riesgo. La transferencia del riesgo, a su vez, tiene consecuencias para la impugnación del contrato de compraventa por error: cuanto más amplios sean los efectos jurídicos del contrato de compraventa, es decir, cuanto más "francés" sea el contrato, más estable deberá ser, y viceversa.

Causa formalis: cuando se habla de "eficiencia sistemática" se alude, antes que todo, al hecho de que una determinada regla es aplicable al mayor número posible de casos y, por lo tanto, necesita el menor número de excepciones. Entonces, es una cuestión de economía y de fácil manejo de la ley ${ }^{79}$. Uno de los argumentos clásicos ${ }^{80}$ en contra del principio del consensualismo francés, y que también ha encontrado apoyo entre los redactores del $\mathrm{DCFR}^{81}$, afirma que este principio necesita una adecuación para el caso de cosas genéricas o de cosas aún por fabricar ${ }^{82}$. Frente a este argumento cabe preguntarse si acaso los otros sistemas no requieren ajustes ni excepciones. $\mathrm{Al}$ parecer, estamos tan acostumbrados a las excepciones de nuestros propios sistemas que apenas las percibimos

\footnotetext{
${ }^{79}$ Véase GuZmán Brito (1977), p. 12 y s.

${ }^{80}$ BuCher (1998), pp. 614, 618; VON CAEMMERER (1938/1939), pp. 675, 689.

${ }^{81}$ LuRger y FABer (2011), p. 413 y ss.

${ }^{82}$ Véase la ficción del art. 1585 Code Civil.
}

como tales -basta pensar en el constituto posesorio, que se opone de manera radical al principio de la traditio $^{83}$. Sin embargo, la eficiencia sistemática es naturalmente un ideal al que vale la pena aspirar. Y la solución que se encuentra en el DCFR también está (como se mostrará infra, sub III. 1) vinculada a este ideal, en la medida que disuelve la contradicción entre el principio de la traditioy el constituto posesorio.

No menos importante es la consecuencia sistemática. En efecto, las conclusiones que se extraen del sistema no son juicios de valor, como la preferencia que se da a determinados intereses, sino que razonamientos verificables, como aquel que, desde los dos lados de un triángulo, y del ángulo que forman, calcula, por deducción, los ángulos restantes, para usar el ejemplo de Friedrich Carl von Savigny ${ }^{84}$. La razón de la fuerza persuasiva de estas conclusiones radica en que se pueden verificar según el criterio de la justicia sistemática que, a su vez, se define por los principios de unidad y de orden ${ }^{85}$. Sin embargo, los argumentos de consecuencia sistemática solo son útiles cuando se aceptan como dados aquellos

${ }^{83}$ La admisibilidad de una entrega en la forma de constitutum possessorium fue, no por casualidad, una de las razones por la que los redactores del Code civil adoptaron el principio del consensualismo: en la práctica notarial francesa del tiempo del Code era común que las partes sustituyeran la entrega formal, sobre todo en el caso de los bienes inmuebles, con formas similares de entrega ficta. Teniendo esto presente, se puede comprender el principio del consensualismo como una codificación de la práctica notarial prerevolucionaria; véase al respecto, VAN VLIET (2000), p. 76 y ss.

${ }^{84}$ Von Savigny (1840), p. 22.

${ }^{85}$ Canaris (1983) y Martens (2013), p. 407 
elementos del sistema desde los que se infieren conclusiones sobre los demás. $\mathrm{Si}$ se aplica este procedimiento a la transferencia de la propiedad, se debe suponer que su ese aspecto real constituye la piedra clave y no los cimientos de una codificación del derecho de compraventa. Esta suposición es fundada: el traspaso de propiedad de la cosa vendida, cualquiera sea el modo en que se realice, sirve solo para dar ejecución al contrato que está en la base ${ }^{86}$, pero, por cierto, no representa una razón jurídicamente fundada para retener la cosa. En caso de que el negocio causal sea ineficaz, esto se manifiesta en la permanencia de la cosa en propiedad del vendedor o en el reconocimiento de una pretensión restitutoria, según el sistema en el que uno se encuentre ${ }^{87}$. El derecho de bienes es el ejecutor de las decisiones tomadas a través de contratos de compraventa (y, en general, del Derecho de Obligaciones), pero en la ejecución de estas decisiones el Derecho de Bienes tiene una competencia muy limitada, sobre todo porque le está vedado imponer sus propios juicios de valor: lo opuesto no sería conciliable con la autonomía privada. Por lo tanto, la cuestión sobre la atribución de la propiedad está en una relación de dependencia teleológica respecto al contrato de compraventa de lo que ulteriormente se deduce que las reglas sobre el traspaso de la propiedad no son correctas o falsas a priori ${ }^{88}$, sino que 20.

${ }^{86}$ ERnst (2012), antes de $§ 241$ parágrafo

${ }^{87}$ Kegel (1977), pp. 57, 65.

${ }^{88}$ Flume (1992), § 12 III 3. En un sentido análogo, véase Strohal (1889), pp. 335, 336; Kegel (1977), p. 78 y MaYer-MaLy (1990), pp. 275, 285. solo a posteriori, es decir, dentro de un sistema dado y preestablecido ${ }^{89}$.

Por lo tanto, en el capítulo siguiente (II) se partirá de las decisiones básicas del DCFR y del CESL para obtener, por vía sistemático-teleológica, las reglas precisas para la transferencia de la propiedad. En el capítulo subsiguiente (III), los resultados alcanzados serán comparados con la solución adoptada por el DCFR para verificar la coherencia sistemática. Luego este resultado será confrontado con el CESL.

\section{LA DETERMINACIÓN}

DE LAS REGLAS CORRECTAS

PARA LA TRANSFERENCIA

DE LA PROPIEDAD EN LA COMPRAVENTA

$$
\begin{aligned}
& \text { 1. La necesidad } \\
& \text { de un acuerdo real de transferencia } \\
& \text { (dinglicher Vertrag) }
\end{aligned}
$$

\section{a) Code civil y $B G B$ :}

Acto jurídico y relación jurídica

Al comienzo de la Edad Moderna, el Derecho Natural era la escuela dominante en el pensamiento jurídico europeo y tuvo una notable influencia en el Code Civil, de manera que también representó un papel decisivo en la formación del sistema del consensualismo ${ }^{90}$. Según Hugo Grocio, el más influyente pensador iusnaturalista, "contrato" significa que se ofrece una particula libertatis y se enajena al adquiriente ${ }^{91}$. Ahora, si el

\footnotetext{
${ }^{89}$ Fundamental, al respecto, Esser (1972), p. 15.

${ }^{90}$ BuCHER (1998), pp. 614, 657; véase también a Petronio (1991), pp. 169, 171 y ss.

${ }^{91}$ Grotius (1735), II, 11, 4. 1; seguido por Von Pufendorf (1795), III, 5, 7; al respecto,
} 
contrato de compraventa, al igual que los otros contratos, tiene por su misma esencia la enajenación, no es necesario convertir, adicionalmente, la entrega de la cosa un presupuesto de la transferencia de la propiedad ${ }^{92}$. Si se considera, además, que el constituto posesorio equivale a una transferencia consensual de la propiedad, debe eliminarse el requisito de la entrega -y es exactamente esta la conclusión a la que llegó también Hugo Grocio ${ }^{93}$.

Por el contrario, la teoría del contrato de Friedrich C. von Savigny, que tuvo una influencia decisiva en el $B G B$, se funda en la formación de una "relación jurídica" entre las partes. "Contrato" no significa una enajenación de liber$\operatorname{tad}^{94}$, sino que un vínculo hacia algo nuevo ${ }^{95}$. Por lo tanto, el contrato transforma acciones,

"que hasta ese momento debían entenderse como sucesos futuros casuales e inciertos, en sucesos necesarios y ciertos" ${ }^{\prime 96}$.

De esto deduce Friederich C. von Savigny que la entrega de una cosa con el objeto de transferir el dominio debe

véase a CoIng (1985), p. 393; Ehmann (1853), p. 4 y ss. y WiEACKeR (1974), p. 7 y ss.

${ }_{92}$ Al respecto, véase LANDAU (1973), pp. 117,136 y s.

${ }^{93}$ Grotius (1735), II, 6, 1; II, 8, 25; II, 11, 1 ; II, 12, 15, 1: "De venditione \& emtione notandum, etiam sine traditione, ipso contractus momento transferri dominium posse, atque id esse simplicissimum", véase n. 89

${ }^{94}$ Schmiduin (1999), pp. 197, 199 y ss.; en sentido contrario, véase ahora a EHMANN (1853), pp. 12 y ss. y 21 y ss.

${ }^{95}$ Von SAVIGnY (1840), p. 309. Sobre la construcción de la relación jurídica, ver ahora a BOENTE (2013), pp. 56 ss.

${ }^{96}$ Von SaVigny (1840), pp. 8 y s. ser en sí misma un acuerdo -como decimos hoy- real (dinglicher Vertrag) ${ }^{97}$.

Por un lado, tenemos una opinión según la cual el contrato mismo de compraventa tiene la naturaleza de enajenación y, por otro, aquella que sostiene que el contrato de compraventa solo crea una relación jurídica, de la que se deriva, como consecuencia posible, pero no necesaria, la transferencia de la propiedad ${ }^{98}$. Se podría decir que el Derecho francés comprende el contrato de compraventa como "acto jurídico" (Rechtsakt), mientras que el Derecho alemán lo considera una "relación jurídica" (Rechtsverhältnis), en el sentido de Werner Flume ${ }^{99}$.

Esto se puede confirmar comparando las cuatro normas cruciales: el art. 711 del $C c$ establece:

"La propiedad de los bienes se adquiere y se transfiere... por el efecto de las obligaciones" ${ }^{100}$.

Por el contrario, el $\S 241$ del $B G B$ consagra que:

"por fuerza de la relación jurídica el acreedor tiene el derecho de exigir del deudor una prestación"101.

${ }^{97}$ Von SAVigny (1840), p. 312.

${ }^{98}$ Flume (1990), pp. 53 y ss. y 111 y ss.

${ }^{99}$ Sobre esta distinción, véase FLume (1990), p. $9 \mathrm{y}$ ss.

100 "La propriété des biens s'acquiert et se transmet [...] par l'effet des obligations".

101 "Kraft des Schuldverhältnisses ist der Gläubiger berechtigt, von dem Schuldner eine Leistung zu fordern”. Sobre los principios de unidad y de separación, es instructiva la lectura de LARENZ (1986), § 39; estas correlaciones se explican, desde una perspectiva histórica, por SCHMidLIN (1990), p. 305 y ss. 
Respecto a la compraventa, el art. 1583 del $C C$ dispone:

"Ella [la compraventa] es perfecta entre las partes, y la propiedad es adquirida de derecho por el comprador respecto al vendedor, desde que se ha convenido en la cosa y el precio, aunque la cosa no haya sido aún entregada ni el precio pagado" 102 .

Completamente distinta es la formulación del $\S 433$, inc. 1 , frase 1 del $B G B$ :

"con el contrato de compraventa el vendedor de una cosa se obliga a entregar la cosa al comprador y a procurarle la propiedad de la cosa" ${ }^{103}$.

Es evidente que la teoría francesa del contrato no permite la elaboración de un acuerdo real en sí mismo y que, a la inversa, la elaboración de un acuerdo real en sí mismo es la consecuencia obvia de la teoría del contrato del $B G B^{104}$.

¿Cuál de estas dos teorías del contrato es más cercana, entonces, al DCFR? El art. II.-1:101(1) del CFR señala:

102 "Elle [la vente] est parfaite entre les parties, et la propriété est acquise de droit à l'acheteur à l'égard du vendeur, dès qu'on est convenu de la chose et du prix, quoique la chose n'ait pas encore été livrée ni le prix payé".

103 "Durch den Kaufvertrag wird der Verkäufer einer Sache verpflichtet, dem Käufer die Sache zu übergeben und das Eigentum an der Sache zu verschaffen".

${ }^{104}$ Véase al respecto CoIng (1986), p. 394 y Jakobs (2002), pp. 269, 300 y s.
"Un contrato es un acuerdo que está destinado a crear una relación legal vinculante o a tener otro efecto legal” ${ }^{105}$.

Esta definición suena como una evidente traducción de la definición de contrato de Friederich C. von Savigny ${ }^{106}$. Una impresión que se refuerza por la circunstancia, cuyo alcance no debe subestimarse, que dicha norma contiene, en el segundo inciso, una definición de negocio jurídico:

"Un acto jurídico es cualquier declaración o acuerdo, expreso o implícito de la conducta, que está destinado a producir efecto legal por sí mismo. Puede ser unilateral, bilateral o multilateral” ${ }^{107}$.

El DCFR se revela, de esta manera, como "un $B G B$ traducido al inglés" Si luego se toma en consideración la regulación de la compraventa en el DCFR, el resultado se ve confirmado. El art. IV.A.-1:202 prevé:

105 "A contract is an agreement which is intended to give rise to a binding legal relationship or to have some other legal effect".

${ }^{106}$ Sobre esta definición, véase en particular JANSEN y ZIMMERMANN (2010), pp. 197, 207 y ss.

107 "A juridical act is any statement or agreement, whether expressed or implied from conduct, which is intended to have legal effect as such. It may be unilateral, bilateral or multilateral". A propósito, véase VAN VLIET (2011), pp. 292, 297 y ss.

${ }^{108}$ Ernst (2009), pp. 55, 70; semejante es la opinión de Jansen y Zimmermann (2010), pp. 196, 204 y Pelloso (2012), pp. 1, 11; en general, respecto al nexo existente entre el negocio jurídico y la Pandectística, véase STAGL (2007), p. 37. 
"Un contrato para la compraventa de bienes es un contrato por el cual una parte, el vendedor, se obliga con otra parte, el comprador, a transferirle la propiedad de los bienes al comprador, o a un tercera, sea inmediatamente a la celebración del contrato o en un momento futuro, y el comprador se obliga a pagar el precio" 109 .

Por consiguiente, en el catálogo de las obligaciones del vendedor contenido en el art. IV.A.-2:101 se lee la frase:

"El vendedor está obligado (a) transferir la propiedad de los bienes" ${ }^{110}$.

Una obligación de transferir la propie244 dad (must) tendría muy poco sentido si el contrato de compraventa tuviese un effet translatif, porque la propiedad pasaría entonces al momento de la celebración del contrato de compraventa. Pero, sobre todo, la regulación de la transferencia de la propiedad en la compraventa contenida en el Arta. VIII.2:101 del DCFR, y el que se tratará sub III. 1, no tendría ningún sentido si la transferencia de la propiedad fuera inherente al contrato de compraventa según el modelo francés. Una defini-

109 "A contract for the 'sale' of goods is a contract under which one party, the seller, undertakes to another party, the buyer, to transfer the ownership of the goods to the buyer, or to a third person, either immediately on conclusion of the contract or at some future time, and the buyer undertakes to pay the price".

110 "The seller must: (a) transfer the ownership of the goods; [...]".

ción de contrato de compraventa casi idéntica en palabras, y que alude a una situación jurídica paralela, encontramos en el art. $2(\mathrm{k})$ de la PR CESL:

“"contrato de compraventa' significa cualquier contrato por el cual el tradente ('el vendedor') transfiere o se obliga a transferir la propiedad de los bienes a otra persona ('el comprador'), y el comprador paga o se obliga a pagar su precio"111.

Si se considera de manera aislada, esta definición podría ser entendida como si el contrato de compraventa, en el CESL, estuviera dotado por un effet translatif. Existen tres argumentos al contrario:

- En primer lugar, el CESL no regula la transferencia de la propiedad en la compraven$\mathrm{ta}^{112}$. Por lo tanto, tampoco señala que el contrato de compraventa transfiere el dominio usando una expresión que correspondería a la concepción francesa (arg. ex art. 711 del $C C)$, sino que, más bien, dice que el vendedor transfiere la propiedad (the seller transfers the ownership of the goods). Esta formulación, que pone en primer plano al sujeto que realiza el acto de autonomía privada, corresponde a la concepción

111 “'sales contract' means any contract under which the trader ('the seller') transfers [sic] or undertakes to transfer the ownership of the goods to another person ('the buyer'), and the buyer pays or undertakes to pay the price thereof; [...]".

${ }^{112}$ Para las referencias, véase supra n. 8. 
alemana del contrato de compraventa.

- En segundo lugar, es evidente que la formulación "transfiere la propiedad" (transfers ownership) en el CESL tiene como única función reproducir la expresión "sea inmediatamente junto con la celebración del contrato" (either immediately on conclusion of the contract) del art. IV.A.-1:202 del DCFR. El CESL entonces es un escalón textual (Textstufe) del $\mathrm{DCFR}^{113}$. A qué alude después el "inmediatamente" (immediately), lo aclaran los materiales de comentario al. IV.A.1:202 del DCFR:

"By including both cases in which the seller is to transfer ownership immediately and those in which ownership is to be transferred at some future time, paragraph (2) ensures, first of all, that the present rules apply both to sales transactions where ownership passes immediately on conclusion of the contract, for instance at supermarkets, petrol stations or other self-service stores, and to sales transactions where this is not the case, for instance when the contract concerns the sale of goods that are not yet in existence or contains a retention of ownership clause" ${ }^{114}$.

${ }^{113}$ Véase al respecto EIDENMÜLLER, JANSEN, Kieninger, Wagner y Zimmermann (2012), pp. 269, 270 y s.

${ }^{114}$ Véase Von Bar y Clive (2009), p. 1259.
De ninguna manera se trata, entonces, de incorporar el efecto translaticio (effet translatif) del Code Civil, sino solo dejar claro que la regulación del contrato de compraventa también se aplica a los casos que, cum grano salis, podrían entrar en la categoría de la compra en efectivo (Barkauf). También estos casos pueden caber en el ámbito de aplicación del CESL, en cuanto el presupuesto, exigido por el CESL, que el contrato sea de carácter "transfronterizo" (cross-border), en las relaciones con los consumidores a se cumple cuando el consumidor, por ejemplo, tiene su dirección de facturación en un país diferente al del proveedor (art. $4 \mathrm{~N}^{\mathrm{O}} 3(\mathrm{a})$ de la PR CESL).

- En tercer lugar, un modo similar de comprender el art. 2(k) de la PR CESL sería contradictoria con la definición de las obligaciones principales del vendedor, la que está prescrita en el art. 91 del CESL:

"El vendedor de bienes [...] deberá: a) entregar los bienes o [...]; b) transmitir la propiedad de los bienes" $" 15$.

Esta definición adopta la palabra 'deber' del art. IV.A.-1:101 del DCFR, y esto, como se ha dicho, no tendría sentido si el

115 "The seller of goods or the supplier of digital content (in this part referred to as 'the seller') must: (a) deliver the goods[...]; (b) transfer the ownership of the goods [...]." 
contrato de compraventa fuera capaz de transferir la propiedad.

b) Derecho de las Obligaciones y Derecho de Bienes como categorías separadas

La forma en que están estructurados los distintos códigos nacionales confirma los resultados alcanzados hasta ahora: En su estructura, el Code Civil tiende a no distinguir claramente entre Derecho de las Obligaciones y Derecho de Bienes y, en consecuencia, dota al contrato de compraventa de un efecto real. El Code regula, de hecho, las relaciones jurídicas relativas a las personas, después las relativas a las cosas y, por último, las diferentes maneras por las cuales se adquiere la propiedad (différentes manières dont on acquiert la propriété). En este tercer y último libro están regulados tanto el Derecho de Sucesión como los contratos en general y en particular.

Si el Code civil tratara el contrato de compraventa bajo dicho título del libro tercero y sin darle, a la vez, un efecto traslativo, habría una fisura del sistema ${ }^{116}$. $\mathrm{Si}$, en cambio, se considera la atribución de los bienes a las personas como un área del Derecho distinta al Derecho de las Obligaciones ${ }^{117}$, es consecuencia necesaria no concebir la transferencia de la propiedad sobre la cosa comprada como efecto del negocio causal, sino que, más

${ }^{116}$ El Código Civil de los Países Bajos (Burgerlijk Wetboek) selecciona una vía intermedia. Bajo la general noción de "derecho patrimonial" trata, de hecho: 1) esta materia en general (libro 3); 2) el derecho de las sucesiones (libro 4); 3) el derecho de los bienes (libro 5); y por último, 4) el derecho de las obligaciones (libros 6 a 8).

${ }^{117}$ Relación de motivación (Motive) de la

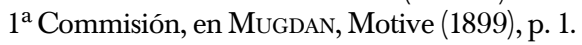

bien, someterlo a la regulación específica de la atribución de los bienes ${ }^{118}$.

Pero al someter la transferencia de la propiedad en la compraventa al Derecho de Bienes, surge la necesidad de un otro contrato como requisito adicional para considerar perfeccionado el traspaso de la propiedad: nótese que los efectos jurídicos del contrato de compraventa se han consumado. Sin acuerdo real la transferencia de la propiedad no tendría, por así decirlo, causa alguna. $\mathrm{El}$ acuerdo real es, por tanto, el correlato necesario de un derecho de bienes "soberano"119.

¿Qué conclusiones se pueden sacar de la actual estructura del DFRC respecto de la existencia de un derecho de bienes que se basta a sí mismo $y$, en consecuencia, del acuerdo real?

El libro I regula las materias que coinciden en gran medida con las de la parte general del $B G B$, los libros II y III regulan el Derecho de las Obligaciones (parte general) ${ }^{120}$, los libros IV al VII el Derecho de las obligaciones (parte especial), incluido el enriqueci-

118 "Para conservar la autonomía, el Derecho de los Bienes debe organizar la adquisición de los derechos reales según puntos de vista que estén en el mismo campo"; así la $1^{\text {a }}$ Commisión, Mugdan, Motive (1899), pp. 2, 4, donde se lee que un ius ad rem, como aquel que reconoce la teoría del titulus y del modus, "ofuscaría [...] la esencia de las relaciones".

${ }^{119}$ Detenidamente sobre el punto, JAKOBS (2002), pp. 269, 287 y ss.; la mismaidea también en BRANDT (1940), p. 66 y s., que trae a la vista a Friederich C. von Savigny; se ve también la firmeza con la que la $1^{\text {a }}$ Comisión defiende la autonomía del Derecho de Bienes respecto al Derecho de Obligaciones: Mugdan, Motive (1899), pp. 2, 5.

${ }^{120}$ Así también Eidenmüller, FAust, GRIGOLeIt, Jansen, Wagner y Zimmermann (2008), pp. 529, 531 . 
miento sin causa y la responsabilidad extracontractual (ilícito civil). El libro IX regula las garantías del crédito y el libro x la propiedad fiduciaria. Este es, incluso en los detalles, el mismo orden que sigue el $B G B^{121}$.

El sistema exterior del DCFR confirma la conclusión en favor del acuerdo real. Respecto al CESL se puede extraer una conclusión análoga, toda vez que también está orientado hacia una separación nítida entre el Derecho de Obligaciones y el Derecho de Bienes.

Además, el acuerdo real da a las partes la posibilidad de pactar reglas diferenciadas para el negocio causal y para el acuerdo real-sobre todo en cuanto a condiciones- $y$ enriquece, por tanto, la libertad para determinar el contenido del contrato en el ejercicio de la autonomía privada ${ }^{122}$.

Para construir la reserva de dominio en el marco del DCFR no se necesita el acuerdo real ${ }^{123}$, dado que está regulada expresamente en el art. IX.-1:103 ${ }^{124}$; sin embargo, esta disposición podría entenderse como un reconocimiento indirecto del acuerdo real.

\section{La entrega como base para presumir el acuerdo}

a) La entrega:

Un correlato del acuerdo real

El $B G B$ requiere una entrega en sentido técnico, pero admite, como "sustituto

${ }^{121}$ Esta es la opinión también de ZimmerMANN y JANSEN (2009), pp. 3401, 3405 y s.

${ }_{122}$ En este sentido también KNÜTEL (2013), pp. 287, 301; VON CAEMMERER (1938/39), p. 675.

${ }^{123}$ Huber (2007), p. 502 y s.

${ }^{124}$ Véase ahora, a propósito FABER (2013), pp. 341, 424 y ss. de la entrega", el constituto posesorio. De manera alternativa, se podría requerir solo un acuerdo real y considerar, a su vez, la entrega como un "sustituto del acuerdo". Ambas figuras serían coherentes con un derecho de bienes "soberano". Si no se opta por una de estas dos soluciones, la transferencia de la propiedad necesariamente se traslada al contrato de compraventa.

La entrega es, en consecuencia, independiente de cualquier consideración relacionada con la publicidad, el correlato necesario del acuerdo real.

De la separación entre el Derecho de las Obligaciones y el Derecho de Bienes, que está en la base del DCFR y del CESL, se desprende un argumento adicional en favor del requisito de la traditio: esta separación solo tiene sentido si su significado no se agota en una mera ordenación de la materia, sino que se relaciona también con una diferenciación lógico-sustancial. Y esta no puede sino consistir en el hecho de que el Derecho de las Obligaciones se interesa por la relación entre dos o más personas y esta relación, en principio, no concierne a terceros, mientras que el Derecho de Bienes regula relaciones que, en principio, afectan a terceros ${ }^{125}$.

${ }^{125}$ Véase también a Von Bar y DrobNIG (2004), p. 323: "The latter [contractual rights] constitute a bilateral relation between two parties and do not, as a rule, affect, or require respect by third persons. By contrast, property rights may affect, and must be respected by any third person whosoever comes in contact with a particular asset". Dado que estos dos autores fueron miembros del Study Group, esta afirmación puede ser considerada como una posición del mismo Study Group. No es sustancialmente distinto el modo en que la $1^{\text {a }}$ Comisión describe la diferencia entre derecho de bienes y derecho de obligaciones: Mugdan, Motive (1899), p. 1. 
La existencia de un derecho de bienes autónomo y autosuficiente es, entonces, determinante para la existencia de un derecho de propiedad con eficacia frente a toda persona. Este, sin embargo, no es compatible con el principio del consensualismo. De hecho, como nos enseña el Code Civil, la propiedad transferida mediante el mero consentimiento es, en muchos casos, solo un derecho relativo ${ }^{126}$.

No hay nada que lo muestre con mayor claridad que la regulación de la compraventa doble contenida en el art. 1141 del $C C$ : en este caso, quien adquiere la "verdadera" propiedad de la cosa es aquel que entra en posesión. En consecuencia, el art. 2279 del $C C$ reconoce al comprador la acción reivindicatoria solo si ha sido poseedor de la $\cos ^{127}$. Por lo tanto, antes de entrar en posesión 248 hay solo una propiedad relativa. Pero la creación de una propiedad de este tipo, con mera eficacia inter partes, anula la nitidez categórica del Derecho de Bienes, que justamente trata derechos oponibles a cualquiera ${ }^{128}$.

\section{b)Atribución de la propiedad y traspaso del riesgo}

Desde un punto de vista histórico, mucho apunta a que el principio con-

${ }^{126}$ No por nada, después de la entrada en vigencia del Code Civil era controvertido si la propiedad transferida con el contrato de compraventa tenía efectos solo inter partes o erga omnes; para las referencias, véase PETRONIO (1991), pp. 169, 172; sobre la posición débil del adquiriente antes de la entrega, véase también Von Caemmerer (1938/1939), pp. 675, 686.

${ }^{127}$ Code Civil, édition Dalloz (2011), art. 2279 parágrafo 3; Von CAEMMERER (1938/1939), pp. 675,686 .

${ }^{128}$ Con análoga argumentación, véase Michaels (2002), p. 216 y ss. sensualista francés deriva sobre todo de la distribución del riesgo de contraprestación en el Derecho Romano ${ }^{129}$ : ya con el perfeccionamiento del contrato de compraventa el comprador debía soportar el riesgo del precio, esto es, debía pagar el precio de la compraventa, incluso, en caso de que la cosa hubiera perecido por caso fortuito: Periculum est emptoris ${ }^{130}$. Esta regla fue recogida en el Code Civil ${ }^{31}$.

Igualmente fue recogida la regla del riesgo respecto a la cosa: Casum sentit dominus $^{132}$.

Si se ponen estas dos reglas una debajo de la otra, como en un silogismo, se llega a la conclusión de que el comprador se convierte en propietario de la cosa con la celebración del contrato $^{133}$, y por esto los franceses formularon su regla del riesgo de la cosa en la compraventa también con el brocardo: Res domino perit ${ }^{134}$.

Existe una íntima relación entre traspaso del riesgo y traspaso de la propiedad. De hecho, si se acepta que el comprador asuma el riesgo de inmediato, sin duda es equitativo recompensarlo convirtiéndolo, también de inmediato, en propietario.

No es casual que Bernhard Windscheid haya enseñado, con referencia al Derecho Romano clásico, que con

${ }_{129}$ Así, de modo convincente Bucher (1998), pp. 615, 651 y ss.

${ }^{130}$ Sobre el contrato de compraventa, en particular, sobre la asunción del riesgo en el Derecho Romano, véase KASER y KNÜTEL (2013), $\S 41$, y ERNST (1982), p. 216 y ss.

${ }_{131}$ Art. 1624, en relación con lo dispuesto en el art. 1138, inc. 2, del Code Civil.

${ }^{132}$ Lo que se deduce también del art. 1138; Ferid y Sonnenberger (1986), p. 231.

${ }^{133}$ Sobre este vínculo, véase también a KEGEL (1977), pp. 57, 75.

${ }^{134}$ Malaurie y Aynès (2012), p. 165 y s. 
la celebración del contrato de compraventa la cosa no entraría en la propiedad del comprador, pero sí en su "patrimonio" (Vermögen) $)^{135}$.

Debido a esta estrecha relación entre asunción del riesgo y propiedad, es posible hacer deducciones sobre la transferencia de la propiedad a partir de las reglas del traspaso del riesgo, y bajo el $\S 446$ del $B G B$, el riesgo y la propiedad, por regla general, se traspasan de manera simultánea, precisamente en el momento de la entrega (cfr. § 929, frase 1, del $B G B$ ).

$\mathrm{El}$ art. IV.A.-5:102(1) del DCFR señala que el riesgo de pérdida o deterioro de la cosa por caso fortuito se traslada recién con su entrega. La misma norma se encuentra en el art. 142 y s. del CESL ${ }^{136}$. Pero si recién desde la entrega el riesgo es de cargo del comprador, no existe ningún motivo para otorgarle la propiedad antes de este momento.

Por el contrario, todo indica que el comprador, si asume el riesgo desde la entrega, debiese convertirse propietario solo al momento de la entrega ${ }^{137}$, "porque los beneficios corresponden a aquel que soporta el riesgo" como se lee en las Instituciones con referencia al contrato de compraventa ${ }^{138}$. Así, la entrega de la cosa se convierte en requisito necesario para la transfe-

${ }^{135}$ Así ERnst (1982), pp. 216, 243 y ss., llamándose a WindSCHEID y KIPP (1906), § 390. Después, en el Derecho posclásico, también se pasó a la transferencia de la propiedad con la compraventa; KASER y KNÜTEL (2013), § 24 parágrafo 14 .

${ }^{136}$ Véase al respecto, LoREnZ (2012), pp. 821 y ss. y 830 .

${ }^{137}$ Véase también Ranieri (1997), p. 180.

${ }^{138}$ Institutiones de Justiniano 3, 23, 3. rencia de la propiedad en la medida que vaya asociada con el traspaso del riesgo: y ese es el caso del DCFR y del CESL.

c) La naturaleza jurídica

de la entrega

La traditio siempre ha tenido una función importante, pero su naturaleza jurídica no es clara: ¿es presupuesto de la transferencia voluntaria de la propiedad o es indicio de la voluntad de transferir la propiedad?

A partir de la época del Derecho Romano clásico ${ }^{139}$, el constituto posesorio llegó a consolidarse universalmente ${ }^{140}$. Puesto que el constituto equivale a una transferencia consensual de la cosa, un requisito de la traditio sin sentimentalismos históricos puede continuar teniendo solo la función de una presunción de voluntad de las partes de transferir la propiedad ${ }^{141}$, es decir, una función que puede ser llamada "un sustituto del acuerdo" y que en la práctica, opera como regla probatoria.

\section{La redundancia del principio de abstracción}
a) La tutela del tráfico jurídico -un argumento tautológico

El principio de abstracción protege a los terceros adquirentes de los vicios de la relación entre vendedor y comprador. Una opinión ampliamente difundida en la doctrina alemana busca justificar el principio de abstracción

${ }^{139}$ Digesto 41, 2, 18 pr.; véase sobre este punto, KASER y KNÜTEL (2013), § 20 parágrafo 6.

${ }^{140}$ W ACKE (1974).

${ }^{141}$ Heck (1930), p. 234 y s. 
con la idea, cargada de consideraciones político-económicas, de la tutela del tráfico jurídico ${ }^{142}$. Esta posición no persuade. Por un lado, el efecto de protección ya se alcanza con la regla que permite la adquisición de buena fe por el no propietario ${ }^{143} y$, por el otro, es falaz invocar la "tutela del tráfico". Así lo muestra un célebre caso hipotético de Emil Strohal: A le hace una oferta a $B$ en virtud de la cual $\mathrm{B}$, tras el pago de una suma de dinero, puede adquirir la propiedad del reloj que se encuentra en poder de $\mathrm{B}$. B responde que está de acuerdo con la adquisición del reloj, pero que, teniendo en cuenta una declaración anterior de A, entiende que el reloj es una donación ${ }^{144}$. B acepta, entonces, solo la oferta sobre la transferencia de la propiedad, pero no la oferta de celebrar un contrato de compraventa. Si se toma en serio la tutela del tráfico como razón justificativa del principio de abstracción y, al mismo tiempo, como criterio válido para su interpretación, no hay manera de negar aquí

${ }^{142}$ Este tipo de justificación no se encuentra en Von SAVIGNY (1840), p. 356 y ss. (véase al respecto RANIERI (1977), pp. 90, 102), sino más tarde, por ejemplo, en Von JHERING (1888), pp. 206 y ss. y 213. Más recientemente esta idea fue defendida por Astrid Stadler; véase también Grigoleit (1999), p. 379 y ss.

${ }^{143}$ Este fue uno de los argumentos -desde su punto de vista- fundamentales de la Corte Federal Suiza (Schweizer Bundesgericht) en rechazo del principio de abstracción (BGer 29.11.1929, BGE 55 II 302); En defensa de la abstracción, con referencia al Derecho alemán, véase Stadler (1996), p. 372 y ss. Argumentos análogos a los acá sostenidos emplea HARKE (2012), p. 292 y ss. Sobre el punto, véase ARMGARDT (2007), p. 1006 y ss.

${ }^{144}$ El ejemplo proviene de Strohal (1889), pp. 335, 344. una adquisición de la propiedad por parte de B; de otro modo, los terceros serían perjudicados por un vicio del negocio causal entre $\mathrm{A}$ y $\mathrm{B}^{145}$.

Como muestra el caso, parece que con la tutela del tráfico se alude únicamente a la tutela de los terceros adquirentes. Pero, ¿por qué? A, quien -en virtud del principio de abstracción- pierde la propiedad, también forma parte del tráfico jurídico, y no se divisa razón alguna que lo haga menos merecedor de tutela que el tercero que contrata con $\mathrm{B}$. El argumento de la tutela del tráfico se basa en un concepto de tráfico injustificadamente restringido ${ }^{146}$ y es, en definitiva, tautológico: el "tráfico" es aquel grupo beneficiado por el principio de abstracción.

El principio de abstracción tiene como consecuencia que el comprador se convierta, por regla general, en propietario y esto, a su vez, tiene como consecuencia que un tercero pueda adquirir, sin problemas, el dominio del comprador. Sin embargo, puesto que el Derecho moderno, como también el art. VII.-3:101 del DCFR, admiten la adquisición de buena fe a non domino,

${ }_{145}$ Probablemente, los romanos habrían calificado este último caso como delito, específicamente como furtum; véase, por ejemplo, Digesto 13, 1, 18. Resulta correcto trasladar esta opinión de los juristas romanos al Derecho alemán, como lo hace parte de la doctrina, con la consecuencia de que el acto de transferencia es nulo por ser contrario a las buenas costumbres; Flume (1992), § 125 b), § 188 c) bb); seguido por Jakobs (2002), pp. 269, 322; Strohal (1889), pp. 335, 344 y ss.; sin embargo, la opinión dominante se opone, invocando teoría según la cual el negocio de disposición es "moralmente neutro"; Heinz-Peter Mansel en JAUERNIG (2014), $\S 138$ parágrafo 25 .

${ }^{146} \mathrm{Al}$ respecto, véase STaGL (2011), pp. 530, 536 y s. 
tiene muy poca importancia si el tercero adquiere a non domino o a domino. Donde rige el principio de abstracción, el tercero adquiere por regla general, donde rige el principio de causalidad, en cambio, el tercero solo adquiere si está de buena fe. Los problemas de equidad que genera esta situación jurídica no se pueden resolver sobre la base del principio según el cual los terceros no tienen por qué interesarse por las relaciones obligacionales de aquellos que los precedieron ${ }^{147}$, toda vez que la pregunta si las relaciones entre vendedor y comprador -incluso cuando aún no ha realizado la entregason solo obligacionales o causalmente necesarias para la transferencia de la propiedad, es precisamente el problema en cuestión. Esto se refleja con claridad en otro caso muy discutido: un tercero sabe con certeza que el comprador que retransfiere la cosa está obligado a restituirla al primer vendedor, por ejemplo, porque este ha impugnado $^{148}$, con éxito, el contrato de compraventa invocando un error ${ }^{149}$.

${ }^{147}$ Huber (2007), p. 504.

${ }^{148}$ Recuérdese que en el Derecho alemán la nulidad de un negocio jurídico requiere una declaración de impugnación de la parte afectada.

${ }^{149}$ En Alemania, la opinión dominante sostiene que la impugnación por error solo alcanza el negocio causal, mientras que el acuerdo real y, con ello, la atribución de la propiedad se mantienen, por regla general, intactos; HeinzPeter Mansel en JAUERnig (2014), § 119 parágrafo 16; Jürgen Ellenberger en PALANDT (2014), antes del § 104 parágrafo 23, § 142 parágrafo 2. Sin embargo, Schermaier (2003), §§ 142-144 parágrafo 10 y ss., señala de forma acertada que no es un problema propio del principio de abstracción, sino, más bien, de causalidad. Razonando de esta manera, la opinión dominante parece tratar las cuestiones de causalidad de un modo que refuerza el principio de abstracción.
En este caso, dejar que el tercero, pese a ello, adquiera la propiedad, como enseñan algunos juristas alemanes $^{150}$, es desconocer el deber del Derecho, de "dar a cada uno lo suyo" 151 -no importa si esto es o no útil para el intercambio de bienes ${ }^{152}$. También esta vez los argumentos de política jurídica no nos llevan más lejos: dirijamos nuestra atención hacia los argumentos sistemáticos.

b) Restituciones mutuas mediante reivindicación o 'condictio' Como vimos en el ejemplo del Derecho austríaco, el acuerdo real no necesariamente tiene que ser abstracto, como sostienen los padres del $B G B^{153}$ y Horst H. Jakobs ${ }^{154}$. Es cierto que el principio de abstracción presupone el principio de separación, pero la abstracción no es una consecuencia necesaria del principio de separación ${ }^{155}$. En efecto, como se desprende del argumento de Friederich C. von Savigny, la importancia del acuerdo real radica en que es la única forma
${ }^{150}$ En este sentido, en forma categórica, GRI- GOLEIT (1999), pp. 379, 384; escéptico, STADLER (1996), p. 379 y s.: "caso extremo y excepcional"; en sentido contrario, a pesar de defender el prin- cipio de abstracción, JaKOBS (2002), pp. 269, 322; Kegel (1977), pp. 57, 80, y Strohal (1889), pp. 335,407 y s., concluyen, a partir de este argumen- to, que se debe rechazar del principio de abs- tracción.
${ }^{151}$ Institutiones de Justiniano, 1, 1 pr.
${ }^{152}$ En contra del "destronamiento" de la ciencia jurídica a favor de las ciencias econó- micas, STÜrner (2014), p. 40.
${ }^{153} 1$. Kommission en Mugdan (1899), tomo III p. 4: "Los negocios que pertenecen al derecho de los bienes tienen necesariamente naturale- za abstracta".
${ }^{154}$ JaKobs (2002), pp. 269, 318.
${ }^{155}$ Así también Kegel (1977), pp. 57, 78. 
de explicar la diferencia que significa entregar una cosa en depósito o, por ejemplo, como dote ${ }^{156}$. En esto no tiene nada que ver con la abstracción.

Lo decisivo es saber: cquieren las partes el traspaso de la propiedad, incluso en caso de que la relación causal sea ineficaz? La respuesta dependerá de cuál sea la forma más ventajosa para las partes, en consideración de sus intereses, para deshacer las eventuales prestaciones realizadas en virtud de una relación causal viciada: la condictio -como se sigue del principio de abstracción- o la acción reivindicatoria -como prevén los otros sistemas ${ }^{157}$. En el Derecho alemán, la diferencia fundamental entre las dos pretensiones consiste en que en la reivindicación el adquirente de buena fe puede retener la utilidad y los frutos ${ }^{158}$, mientras que quien está obligado por la condictio los debe restituiir ${ }^{159}$. En cambio, quien está obligado por la condictio puede invocar el empobrecimiento ${ }^{160}$, mientras que esto no está permitido para quien está obligado por vía de reivindicación ${ }^{161}$. Sin embargo, la restitución de las utilidades percibidas no puede ser el criterio decisivo. Esa obligación también podría ser impuesta al obligado de buena fe por reivindicación ${ }^{162}$. Es nece-

${ }^{156}$ Von SAVigny (1853), p. 256.

${ }^{157}$ Huber (2007), p. 471.

${ }^{158} \S \S 987,993$ del $B G B$.

${ }^{159} \S 818$, inc. 1, del $B G B$.

${ }^{160} \mathrm{Ibid}$.

${ }^{161}$ Sobre la ratio legis Kommission, en MugDAN (1899), tomo 1, p. 218 y ss.: no siendo posible saber con exactitud si uno es propietario de una cosa, la función de esta regla es proteger contra las pretensiones indemnizatorias y de enriquecimiento.

${ }^{162}$ La acción reivindicatoria no está regulada en el DCFR. Una opinión escéptica frente sario, por lo tanto, formular hipótesis de casos particularmente significativos, como lo hace Ulrich Huber.

Para justificar el principio de abstracción, Ulrich Huber se refiere al caso decidido por el Reichsgericht en la causa Ansbacher Bordellkauf (en RGZ $75,68)^{163}$ : A es propietario de un burdel. $\mathrm{El}$ poseedor $\mathrm{B}$ enajena el burdel a $\mathrm{C}$, quien le paga a B. A quiere accionar por reivindicación contra $\mathrm{C}$, afirmando que el contrato entre $\mathrm{B}$ y $\mathrm{C}$ sería contrario a las buenas costumbres y, por lo tanto, nulo. Donde se aplica el principio de causalidad, lo puede hacer, ya que $\mathrm{C}$ no ha adquirido la propiedad. Pero así, por un lado, se permitiría que $A$ interviniera en la relación entre $\mathrm{B}$ y $\mathrm{C}$ y, por otro lado, $\mathrm{C}$ tendría que restituir la cosa a $\mathrm{A}$ sin garantía de poder recuperar su dinero de $\mathrm{B}^{164}$. El principio de abstracción evitaría estos problemas. La pretensión de $\mathrm{B}$ y $\mathrm{C}$ de estar protegidos, como en una chambre séparée, de pretensiones de terceros, sin embargo, no está amparado por la ley, ya que su contrato es nulo; además, el Tribunal Supremo Alemán, al aplicar el $\$ 816$, inc. 1, frase $2 \operatorname{del} B G B$, trata la hipótesis de la disposición gratuita de la misma manera que aquella sin causa, lo que tiene como consecuencia que A se podría dirigir directamente a $\mathrm{C}$ sin que este pueda oponerle la prestación hecha a $\mathrm{B}^{165}$.

Además, se puede decir de forma abreviada, que la diferencia entre el

a este trato preferencial del obligado por vía de reivindicación se encuentra en LARENZ y CANARIS (1994), § 74 I 1 a).

${ }^{163}$ RG 17.12.1910 - v 62/10, RGZ 75, 068.

${ }^{164}$ Huber (2007), p. 504 y s.

${ }^{165}$ BGH 12.7.1962 - VII ZR 28/6, BGHZ 37, 368; en Astrid Stadler en Jauernig (2014), $\S 816$ parágrafo 21 , con referencias posteriores. 
principio de abstracción y el principio de causalidad radica en que la restitución sigue las normas del enriquecimiento o a las de la reivindicación, respectivamente: en el Derecho austríaco la reivindicación se complementa con pretensiones fundadas en el enriquecimiento ${ }^{166}$. Recurriendo a estas, se puede pedir la restitución de una prestación en dinero o el valor de una cosa que pereció.

\section{c) Impugnación por error y seguridad jurídica}

En comparación con otros ordenamientos jurídicos, en particular el austríaco ${ }^{167}$ y el suizo ${ }^{168}$, el Derecho alemán conoce una acción de impugnación del contrato por error muy amplia ${ }^{169}$, lo que reduce la estabilidad de la relación contractual. Ahora bien, si esta fragilidad del negocio causal repercutiera de manera directa en la situación jurídica real -justamente aquello que el principio de abstracción impide--, esto podría, de manera efectiva, volver inseguro el tráfico jurídico ${ }^{170}$. Entonces, se puede decir que el principio de abstracción es el correctivo necesario de una teoría del negocio jurídico fuertemente vinculada a la voluntad ${ }^{171}$, entendida

${ }^{166}$ OGH 29.9.1984 - 2 Ob 510/84, SZ 57/44; Peter Rummel en Rummel (2000), § 1431 parágrafo 25 , y $§ 1431$ parágrafo 8 .

$167 \S 871 A B G B$.

${ }^{168}$ Art. 23 y ss. Derecho Suizo de Obligaciones.

${ }^{169} \S 119$ del $B G B$ Ernst Kramer en MÜNCHENER Kommentar $B G B(2012)$, § 119 parágrafo 7 y ss.

${ }^{170}$ En esta dirección argumenta FuUme (1990), § 12 III 3; lo sigue KNÜTEL (2013), p. 302. 300. como "lo único importante y eficaz"172. El DCFR y el CESL establecen una regulación de la impugnación por error que dista bastante de la alemana. El art. II- 7:201 DCFR ${ }^{173}$ y el art. $48 \mathrm{CESL}^{174}$ le imponen, a la impugnación por error, un límite que -desde el punto de vista alemán- es notable: la impugnación solo es posible si la parte contra la que se dirige es responsable del error y la parte facultada para impugnar no tiene el deber de soportar el riesgo del error $^{175}$. Frente a una impugnación tan limitada, no es necesario el principio de abstracción para defender la certeza jurídica $^{176}$.

d) Una primera conclusión:

La navaja de Ockham

Los principales argumentos a favor del principio de abstracción no nos llevan muy lejos, no resisten la crítica o se refieren a casos que se pueden resolver sin su auxilio. Todo esto se podría aceptar, si el principio de abstracción aportara particulares ventajas. Una ventaja solo podría consistir en un aumento de las posibilidades de la au-

\footnotetext{
${ }^{172}$ La formulación es de Von SAVIGNY (1840), p. 258.

${ }^{173}$ Véase a propósito, Eidenmüller, Faust, Grigoleit, JANSEN, Wagner y ZimmermanN (2008), p. 546 y s. y JANSEN y ZiMMERMANN (2010), p. 240 y ss. Menos crítica es la posición de Kramer (2009), pp. 435, 448 y ss.

${ }^{174}$ Véase al respecto Jansen (2012), p. 168; LOOSCHELDERS (2012), pp. 581, 618 y ss.

${ }^{175} \mathrm{Al}$ respecto, véase Pfeiffer (2012), art. 48 parágrafo 38.

${ }^{176}$ Así también se resuelve la preocupación de Flume (1990), § 12 III 3, quien, justamente con referencia a la impugnación por error, sostenía que no se puede pretender que el adquiriente dependa, "de todas las incertezas del negocio causal del adquiriente" en caso de ejecución individual o insolvencia.
} 
tonomía privada: la causalidad se puede pactar, conectando la eficacia de la transferencia de la propiedad con la eficacia del negocio causal; la abstracción, en cambio, supuestamente no se puede pactar. Sin embargo, si alguien quiere efectuar a toda costa un traspaso de propiedad, incluso para el caso que el negocio causal sea ineficaz, puede hacerlo sin impedimento, pactando, con cierta fantasía jurídico-contractual, causas "de reserva" que pueden servir como sustento de la transferencia de la propiedad en caso de la ineficacia de la causa primaria, fabricando, así, por medio de la autonomía privada, la abstracción. Puesto que el principio de abstracción no es requerido ni por el sistema del DCFR ni por el del CESL, y no tiene ventajas particulares, no nos queda sino dejarlo de lado, según el

e) Traspaso de la propiedad y pago del precio como paquete único

Lo opuesto a la abstracción del contrato de compraventa es la transferencia de la propiedad y el pago del precio de venta en un "paquete único" (regla de pago) ${ }^{177}$. En las Instituciones de Justiniano se encuentra un famoso pasaje ${ }^{178}$ que señala que en la compraventa la propiedad solo se traspasa una vez que el comprador haya pagado el precio, aunque se haya hecho la entrega, a menos que

$177 \mathrm{Al}$ respecto, véase Stagl (2015).

${ }^{178}$ Instituciones de Justiniano, 2, 1, 41. Sobre este pasaje y su influencia histórica, ver en particular a FEenstra (1949); HonORÉ (1983), p. 56; LUIG (1985), pp. 445 ss.; VIARO (2011), p. 194; ZiMMERMANN (1990), pp. 272 ss.; ZwALVE y SIRKS (2012), pp. $271 \mathrm{~s}$.

el vendedor hubiese querido ejecutar de manera anticipada su prestación ${ }^{179}$. Sobre esta base, el Derecho Común reconocía la combinación entre traspaso de la propiedad y pago del precio de la compraventa, constituyéndose así una especie de reserva de dominio legal ${ }^{180}$. Sin embargo, había mucha controversia respecto a los casos que podían entenderse como una prestación anticipada del vendedor y, por consiguiente, como traspaso de la propiedad, toda vez que la importancia práctica de la regla del pago depende decisivamente, de que, en casos de entrega anterior al pago, se presuma o no que el vendedor haya querido anticipar su prestación ${ }^{181}$.

La regla del pago se encuentra en algunos derechos, como, por ejemplo, la Coutume de Paris del 1582 (arts. 176 y s.) ${ }^{182}$. En las codificaciones más recientes, a partir de 1800 aproximadamente, ya no fue considerada ${ }^{183}$ y desaparece así en gran medida del mundo jurídi$\mathrm{co}^{184}$. El Derecho Romano-holandés de Sudáfrica constituye de nuevo una excepción, derivada precisamente de las Instituciones de Justiniano ${ }^{185}$.

${ }^{179}$ Instituciones de Justiniano, 2, 1, 41.

${ }^{180}$ Véase al respecto Stagl (2015).

${ }^{181}$ WindsCheID y KIPP (1906), § 172 con n. 7, con referencias adicionales.

${ }^{182}$ Citado por Feenstra (1949), p. 208. Referencias adicionales se encuentran en BRANDT (1940), p. 190 y ss.

${ }^{183}$ Con excepción del $\S 139$, inc. 3, del Código Civil de la República Democrática Alemana del 1975.

${ }^{184}$ En favor de una presunción similar véase Westermann en Münchener Kommentar $B G B$ (2012), § 449 parágrafo 13 y ss.; SCHULTE (1977), p. 269; a las circunstancias del caso particular se remiten Christian Berger en JauerNIG (2014), § 449 parágrafo 6.

${ }^{185}$ Carey Miller (1996), p. 755 y ss., con referencias adicionales; FeEnSTRA (1949), p. 155 
La regla del pago fue rechazada por la $1^{\text {a }}$ Comisión consultiva del $B G B$ con especial hincapié en que la ley no debería fomentar los acuerdos reales sujetos a condición, en cuanto conducirían a "situaciones de pendencia indeseadas" $"$. Si bien la Comisión no lo dijo de forma expresa, es probable que su actitud de rechazo se haya debido, no tanto al temor de situaciones de pendencia indeseadas, sino al hecho de que esta regla naturalmente obstaculiza la autonomía del Derecho de Bienes, y esto es lo que los redactores del $B G B$ querían defender. Dado que el DCFR también se caracteriza por un derecho de bienes autosuficiente, siguiendo la misma lógica también a este le debe repugnar, "en el plano sistemático", la regla del pago. Lo mismo vale para el CESL.

Cabe aclarar que la regla del pago, al crear una interdependencia de las prestaciones, fortalece la igualdad entre las partes, razón por la que Bernhard Windscheid le reconocía una "equidad natural" ${ }^{187}$. El derecho de retención del vendedor consagrado en el art. III.-3:401 del DCFR es expresión de la misma idea jurídica, al igual que el art. 113 N $^{\circ} 1$ del CESL. Sin embargo, no se debería establecer la regla del pago de forma rígida, sino que permitir su implementación caso a caso -nótese que el citado pasaje de las Instituciones, a causa de su ambivalencia, también dejaba amplios márgenes de interpretación.

y ss. con referencias adicionales; ZIMMERMANN (1983), p. 125 y s.; sobre la historia en el Derecho Romano holandés, véase CARey Miller (1996), pp. 521, 531 y ss.

${ }^{186}$ Mugdan, Motive (1899), p. 186.

${ }^{187}$ Windscheid y KipP (1906), § 172.
III. CONCLUSIÓN:

LA TRANSFERENCIA DE LA PROPIEDAD

EN LA COMPRAVENTA

DEL DCFR Y DEL CESL

1. DCFR:

La teoría del título

y el modo en su rol funcional

Veamos ahora cómo las conclusiones a las que hemos llegado desde un punto de vista sistemático y abstracto se relacionan con la regulación efectivamente adoptada en el DCFR.

"Art. VIII. - 2:101 DCFR - Requirements for the transfer of ownership in general

(1) The transfer of ownership of goods under this Chapter requires that:

(a) the goods exist;

(b) the goods are transferable;

(c) the transferor has the right or authority to transfer the ownership;

(d) the transferee is entitled as against the transferor to the transfer of ownership by virtue of a contract or other juridical act, a court order or a rule of law; and

(e) there is an agreement as to the time ownership is to pass and the conditions of this agree ment are met, or, in the absence of such agreement, delivery or an equivalent to delivery [...]". 
En virtud del art. VIII.-2:101(1)(e) del DCFR, la propiedad se traspasa cuando las partes lo quieren o cuando el enajenante entrega la cosa al adquiriente. Pero, ¿cuál es el fundamento del traspaso de propiedad en uno de estos momentos? Si bien los redactores del DCFR lo excluyeron expresamente ${ }^{188}$, solo un acuerdo real permite explicar de manera razonable el traspaso de propiedad sobre la base de esta regla ${ }^{189}$, un acuerdo cuya celebración se presume en caso de una simple entrega, dando lugar a la entrega como "sustituto del acuerdo". Una primera alternativa, aquella del traspaso consensual de la propiedad mediante el contrato de compraventa, está categóricamente excluida a través del art. VIII.-2:101 del DCFR ${ }^{190}$, pero también lo está la segunda alternativa, aquella de la traditio como requisito riguroso de la transferencia. El traspaso de la propiedad, si no es consecuencia ni del contrato de compraventa ni de la entrega entendida como un modo de adquirir, debe ser consecuencia del acuerdo real, porque de lo contrario no se sabría cuándo se traspasa la propiedad. La necesidad del acuerdo real viene, entonces, de la necesidad de establecer el momento del traspaso de propiedad, y esta necesidad es el precio de la libertad, la que consiste en el hecho de que se deja el traspaso de la propiedad enteramente a la discreción de las partes. También la práctica lo confirma. Pensemos en el

\footnotetext{
${ }^{188}$ LURGER y FABER (2011), pp. 410, 444 y ss., 452 .

${ }^{189}$ SALOMONS (2009), pp. 711, 715, 721; VAN VLIET (2011) pp. 292, 296.

190 Sobre estos presupuestos -aquí no satisfechos- del principio del consensualismo, véase MALAURIE y AYNÈs (2012), p. 163; Zoll (2012), art. 91 parágrafo 9.
}

caso en que las partes fijan el momento del traspaso de la propiedad, pero la cosa no es entregada: ¿se transfiere la propiedad? Seguramente no, porque se llegaría a las consecuencias más absurdas. En cambio, y de manera coherente, el art. VIII.-2:104 del DCFR conecta el traspaso de la posesión (delivery) a la voluntad del vendedor: si la cosa pasa al comprador sin el consentimiento del vendedor, la cosa no es "entregada", y la propiedad entonces no se traspasa.

Como era de esperar, el principio de abstracción no prevaleció en el DCFR: pese a que el acuerdo real de las partes está dirigido al mero traspaso de la propiedad, esta solo se transfiere en presencia de un contrato eficaz o de alguna otra causa ${ }^{191}$. Esta regla es coherente con las reflexiones desarrolladas atrás y con el resto de la estructura del DCFR.

Entonces, ¿cómo debe ser encuadrada la transferencia de la propiedad según el DCFR? Los mismos redactores designan su sistema como una "regla de entrega por default" (delivery) default rule $)^{192}$, expresión que pretende, ante todo, dejar en evidencia que la entrega no es un requisito obligatorio sino que se puede prescindir de ella, si las partes lo quieren. Considerando que Philipp Heck había descrito la entrega como el "ropaje histórico" en el que la transferencia consensual de la propiedad aparece en las codificaciones modernas, el mérito de los redactores está sobre todo en haber quitado a la transferencia de la propiedad aquel

${ }^{191}$ En el mismo sentido HaRKE (2012), p. 292 y VAN Vliet (2011), pp. 292, 295. Esta es también la evaluación que de esta regla dan sus mismos redactores: LURGER y FABER (2011), pp. 436.

${ }^{192}$ Lurger y Faber (2011), p. 410. 
ropaje histórico y haberla revestido de un carácter más funcional. El énfasis que de este modo se da a la voluntad de las partes, dejaría a la jurisprudencia la posibilidad de hacer aplicable la regla del pago cuando sea oportuno. En términos generales, los redactores del DCFR, aunque adoptando un método completamente distinto, basado en la ponderación de los intereses contrapuestos, llegan casi a las mismas conclusiones aquí sostenidas, y entonces a un sistema de transferencia de la propiedad similar al existente, por ejemplo, en los Países Bajos o en Austria ${ }^{193}$. Esta armonía en los resultados, aunque con métodos diferentes, quizá se debe a que es difícil permanecer sordos frente a la "melodía rocosa" (Felsenmelodie) ${ }^{194}$ que emana de las estructuras básicas. Llegamos, entonces, a este resultado: la regla del art. VIII-2:101 del DCFR es conforme con el resto del contenido del DCFR, es la clave del arco que de ahí se deriva y, por eso, también la solución correcta.

\section{El CESL: \\ el Derecho de Bienes "durmiente" del DCFR}

El CESL, como se ha dicho, prescinde de una regulación expresa del traspaso de la propiedad y prevé entonces, al igual que el Derecho Internacional Uniforme de la Compraventa de Mercaderías, que corresponde al Derecho Internacional Privado de los Estados miembros determinar si la propiedad se traspasa o no en un caso concreto,

\footnotetext{
${ }^{193}$ Así también las conclusiones de VAN VLIET (2011), pp. 292, 333.

${ }^{194}$ La expresión es de Karl Marx, Briefan den Vater in Trier del 10. 11. 1837, en MARX y ENGELS (1973), vol. 40, pp. 3, 4.
}

el que generalmente ordenará aplicar la lex rei sitae ${ }^{195}$ lo que no puede ser modificado por las partes. Surgen así-a diferencia de lo que sostenía Ernsrt Rabel- una serie de problemas, eminentemente prácticos, en relación con las cuestiones preliminares relacionadas con la regla de la lex rei sitae $e^{196}$, con las garantías reales ${ }^{197}$ y con la adquisición de buena fe de la propiedad ${ }^{198}$, es decir, con los problemas jurídicos de regulación muy variada en los ordenamientos jurídicos nacionales ${ }^{199}$. El Derecho de la Compraventa Internacional no habría podido tener éxito si también hubiera regulado la transferencia de la propiedad, y así tuvo que conformarse con esta solución parcial ${ }^{200}$.

En relación con Europa, es evidente que el Derecho de Compraventa ha sido la primera materia elevada del rango de proyecto al de Derecho vigente, lo que es comprensible considerando que la experiencia histórica demuestra, por ejemplo, en el caso del Código Comercio alemán (Allgemeines Deutsches Handelsgesetzbuch) de 1861, que el contrato de compraventa es, en realidad, el primer paso lógico hacia una codificación europea de Derecho

${ }^{195}$ Referencias en FrancoFerrari enSCHLECHTRIEM y SCHWENZER (2013), art. 4 parágrafo 29.

${ }^{196}$ Gerhard. Hohloch en ERMAN $B G B$, art. 43 EGBGB parágrafos 12-16; nombre Wendehorst en Münchener Kommentar $B G B$ (2010), art. 43 parágrafo 116.

${ }^{197} \mathrm{~V}$., por ejemplo, BGH 2.2.1966 - VIII ZR 153/64, BGHZ 45, pp. 95 ss.

${ }^{198}$ Por ejemplo, BGH 10.6.2009 - VIII ZR 108/07, NJW(2009), p. 2824.

${ }^{199}$ Sobre las garantías, véase DrobNig y Böger (2015); sobre la adquisición de buena fe, véase PRISCHING (2006).

${ }^{200}$ Franco Ferrari en Schlechtriem, SchwenZER (2013), art. 4 parágrafo 29 (véase n. 9). 
Privado que, naturalmente, es la meta que pretende alcanzar el DCFR ${ }^{201}$. No cabe duda que si el CESL entrara en vigencia, muy pronto se alzarían voces exigiendo, justamente en razón de las garantías del crédito y de la adquisición de buena fe $a$ non domino, regular también el aspecto real de la compraventa: a fin de cuentas, el CESL también se aplicaría a los contratos entre empresas y consumidores (art. $4 \mathrm{~N}^{\mathrm{O}} 3$ de la PR CESL) ${ }^{202}$ y no es posible exigirle a estos últimos ingresar en el laberinto del Derecho Internacional Privado, donde prácticamente no existen, ni siquiera en Europa, normas de conflicto uniformes en materia de propiedad y derecho reales ${ }^{203}$. Este es un argumento cuya solidez es difícil de negar, teniendo en cuenta que, debido al principio de abstracción, la ineficacia de la compraventa puede producir consecuencias jurídicas diferentes dependiendo de si, por ejemplo, se vendió de Alemania a Francia o de Francia a Alemania ${ }^{204}$ : En efecto, las reglas de Derecho alemán o francés que, según la regla del situs, sean aplicables, determinarán si, pese a la ausencia de la causa $a^{205}$, la propiedad se traspasa o no se traspasa, respectivamente.

Pero, des absolutamente necesario llegar al punto que los jueces tengan que

${ }^{201}$ Eidenmüller, Faust, Grigoleit, JanSen, Wagner y Zimmermann (2008), pp. 529, 533 y s.

${ }^{202} \mathrm{Al}$ respecto, véase LORENZ (2012), p. 821 y ss.

${ }^{203}$ Una reseña se puede encontrar en Schmidt-Kessel (2005), p. 341.

${ }^{204}$ En detalle GolDt (2002), p. 83 y ss.

${ }^{205}$ En concreto, sobre el problema de la abstracción y de la causalidad, véase Gerhard Hohloch en ERMAN $B G B$, art. 43 EGBGB parágrafo 11 .

lidiar con las complejidades el Derecho Internacional Privado? ¿Acaso no es posible entregarse a la idea, a primera vista extraña, pero, desde una visión pragmática, más bien seductora, que el CESL contenga una regulación del traspaso de la propiedad?206. El intérprete es soberano y, en el ámbito de la ciencia, dispone de "plena autoridad pretoria" (Horst H.Jakobs) $)^{207}$, lo que comúnmente se expresa diciendo que la ley puede ser más sabia que sus mismos creadores ${ }^{208}$. Esta idea tiene su fundamento en el principio enunciado por Tomás de Aquino, según el cual una cosa puede tener una finalidad aun sin estar consciente de ello $^{209}$. La finalidad de una ley puede entonces ser fijada de una manera no considerada por el legislador ${ }^{210}$.

Pongamos entonces nuestra atención en el sistema "inconsciente" de transferencia de la propiedad del CESL: el sistema de consensualismo francés fue excluido del CESL, como se demostró atrás. Por el contrario, en el CESL, como se desprende de la regulación de los deberes principales de prestación del art. 91, se mantiene la idea de una separación radical entre el Derecho de las Obligaciones y el Derecho de Bienes. Como se ha explicado, de esta separación irrefutablemente desciende el acuerdo real. Y este, a su vez, es, de modo necesario, causal, y no abstracto.

${ }^{206}$ Sobre el método objetivo de interpretación, véase BYDLINSKI (1991), p. 425 y ss.; KRAMER (2013), p. 132 y ss.

${ }^{207}$ JAKOBS (1983), p. 134 y ss.

${ }^{208}$ Véase al respecto Meder (2004), p. 106 y ss.

${ }^{209}$ DE AQUino, Tomás, De principiis naturae cap. 3.

${ }^{210}$ Kramer (2013), p. 184 y s. 
Al principio de abstracción se opone, en particular, el estrecho margen de la impugnación por error prescrita en el art. 48 del CESL.

Sobre la base del art. 142 y s. del CESL, el riesgo pasa con la traditio. De esta disposición y del acuerdo real, se puede inferir ${ }^{211}$ la regla de la transferencia de la propiedad por medio de la traditio. Puesto que el estilo del CESL no es historicista sino funcional, se podrá, además, asumir como premisa que la traditio no se debe entender como una regla vinculante que tiene como excepción el constituto posesorio, sino, más bien, solo como regla probatoria (entrega como sustituto del acuerdo), al igual que en el DCFR.

De las decisiones fundamentales del CESL en cuanto a orden sistemático, en particular de la mencionada separación entre Derecho de Obligaciones y Derecho de Bienes, de la concepción del contrato como relación jurídica, de la regulación que conecta el traspaso del riesgo a la entrega y de la limitada relevancia del error, se puede inferir que el CESL contiene una regulación "durmiente" de la transferencia de la propiedad que corresponde a aquella del art. VIII.-2:101 del DCFR. El CESL tiene algunos Aspectos Del Derecho De Bienes en potencia, que por el momento no se ha concretado en un verdadero

${ }^{211}$ La teoría contraria de Tomás MARTínez (2014) de que hay una "desconexión conceptual clara en relación al momento en el que ha de producirse el traslado del riesgo y la propiedad", está basada en una "fallacia naturalistica" en cuanto confunde el ser y el deber ser. Si algunas codificaciones modernas desconectan el traslado del riesgo y de la propiedad lo hacen por motivos pragmáticos y no porque sea una buena solución al problema. precepto normativo vigente, pero que ya ata de manos al futuro legislador europeo respecto de la transferencia de la propiedad en la compraventa: el legislador deberá crear una regulación que sea conforme al DCFR.

Sin embargo, se puede pensar que la Corte de Justicia de la Unión Europea, a la luz del objetivo, autoproclamado por el CESL, de promover la tutela de las libertades fundamentales de circulación de las mercaderías y servicios $^{212}$, y consciente de su tendencia a promover de manera ingeniosa la eficacia del Derecho Comunitario $(\text { effet utile })^{213}$, decida, atendiendo especialmente a razones de protección del consumidor, despertar a la regulación durmiente del CESL de su profundo sueño por medio de la interpretación ${ }^{214}$. De un modo u otro, el CESL aparecerá en el mundo del Derecho acompañado de una parte del Derecho de Bienes del DCFR -después de todo el Derecho es "un sistema que", como decía Heinrich von Dernburg, "tiene la capacidad de completarse por su propia fuerza" ${ }^{215}$.

\section{Bibliografía CITADA}

AQUino, Tomás de. De principiis naturae. AQuino, Tomás de. Summa Theologica. Aristóteles. Metafísica.

${ }^{212}$ Considerando $\mathrm{N}^{\mathrm{O}} 1$ de la PR CESL.

${ }^{213}$ Henninger (2009), p. 289 y ss.; MarTENs (2013), p. 463 y ss., 503 ss.; Potacs (2009), pp. 465-487.

${ }^{214}$ Sobre la "responsabilidad" de la Corte de Justicia de la Unión Europea "en la concretización”, véase GsELL (2014), pp. 99, 114 y ss. ${ }^{215}$ Von Dernburg (1900), p. 82. 
ARMGARDT, Matthias (2007). „Der Schutz des gutgläubigen Erwerbers abhanden gekommener Sachen in den europäischen Rechtsordnungen und das quotale Lösungsrecht". ZEuP. vol. 15.

Atias, Christian (2009). Droit civil/Les bien. $10^{\mathrm{a}}$ ed. Paris: Ed. LexisNexis Litec.

Berger, Christian en Jauernig, Bürgerliches Gesetzbuch (2014). Ed. C.H. Beck. $15^{\mathrm{a}}$ edición.

BetTi, Emilio (1954). Zur Grundlegung einer allgemeinen Auslegungslehre, en FS Ernst Rabel. Tübingen: Ed. Mohr Siebeck. Tomo 2.

BJaRUP, Jes (1978). Skandinavischer Realismus. Freiburg: Ed. Alber.

Blaurock, Uwe (1992). „Wege zur Rechtseinheit im Zivilrecht Europas",
BydLINSKI, Franz (1978). Klang, Kommentar zum Allgemeinen Bürgerlichen Gesetzbuch. $2^{\text {a }}$ ed. Viena: Ed. Manz. Vol. IV/2.

Caemmerer, Ernst von (1938/1939). „Rechtsvergleichung und Reform der Fahrnisübereignung“. RabelsZ vol. 12.

Calboli Montefusco, Lucia (1986). La dottrina degli „status" nella retorica greca e romana. Tübingen: Ed. OlmsWeidmann.

CANARIS, Claus-Wilhelm (1983). Systemdenken und Systembegriff in der Jurisprudenz. $2^{\mathrm{a}}$ ed. Berlin: Ed. Duncker \& Humblot.

Carey Miller, David L. (1991). Corporeal Movables in Scots Law. London: Ed. Thomson/W. Gree.

Carey Miller, David L. (1996). Transfer of Ownership, in Reinhard ZimmerMANN \& Daniel Visser (ed.) Southern Cross-Civil Law and Common Law in South Africa. London: Ed. De Gruyter.

CoIng, Helmut (1974). Methoden der Rechtsvergleichung. Tübingen: Ed. Metzner.

CoIng, Helmut (1985). Europäisches Privatrecht. München: Ed. C.H. Beck. Tomo I.

CoIng, Helmut (1986). Europäisches PriMünchenmo II.

Dernburg, Heinrich von (1900). Pandekten. Berlin: Ed. H.W. Müller. Tomo 1.

BuCHER, Eugen (1998). „Die EigentumsTranslativwirkungen von Schuldverträgen: Das Woher? und Wohin? dieses Modells im Code Civil“. ZEuP vol. 6.

BydLINSKI, Franz (1991). Juristische Methodenlehre und Rechtsbegriff. Viena: Ed. Springer.
Doralt, Walter (2011). „Rote Karte oder grünes Licht für den Blue Button? - Zur Frage eines optionalen Europäischen Vertragsrechts". $A c P$. vol. 211.

Drobnig, Ulrich \& Ole Böger (2015). Proprietary Security inMovable Assets. Ed. Sellier. 
Ehmann, Horst (2010). Die Entwickelung des Versprechensvertrags - gegen die Mystik des Willensvereinigungsmodells, en FS Michalis Stathopoulos. Separatum.

Eidenmüller, Horst, Florian Faust, Hans Cristoph Grigoleit, Nils JaNSEn, Gerhard Wagner, Reinhard Zimmermann (2008). „Der Gemeinsame Referenzrahmen für das Europäische Privatrecht“. JZ..

Eidenmüller, Horst, Nils Jansen, EvaMaria Kieninger, Gerhard WAGNer und Reinhard Zimmermann (2012). „Der Vorschlag für eine Verordnung über ein Gemeinsames Europäisches Vertragsrecht Defizite der neusten Textstufe des europäischen Vertragsrechts“. JZ

ERnST, Wolfgang (1982). „Periculum est emptoris“. $Z R G R A$. vol. 99.

ERnst, Wolfgang (2007). Gelehrtes Recht, Jurisprudenz aus der Sicht des Zivilrechtslehrers, in Christoph ENGEL und Wolfgang ScHÖN (ed.) Das Proprium der Rechtswissenschaft. Tübingen: Mohr Siebeck.

ERnst, Wolfgang (2008). „Der ,Common Frame of Reference' aus juristischer Sicht". AcP. vol. 208.

ERnst, Wolfgang (2009). Zur Struktur des CFR, in Martin Schmidt-Kessel. (ed.) Der gemeinsame Referenzrahmen. Tübingen: Ed. Mohr Siebeck.

ERNST, Wolfgang (2012). Münchener Kommentar zum Bürgerlichen Gesetzbuch. $6^{\mathrm{a}}$ ed. Berlin: Ed. C.H. Beck.

Esser, Josef (1972). Methodik des Privatrechts, en Enzyklopädie der geisteswissenschaftlichen Arbeitsmethoden. Tübingen: Ed. Von Manfred Thiel.

FABER, Wolfgang (2008). "Scepticism about the Functional Approach from a Unitary Perspective", in Bri- gitta LuRger \& Wolfgang FABER (eds.). Rules for the transfer of movables. Tübingen: Ed. Seiller.

FABER, Wolfgang (2013). „Das Mobiliarsicherungsrecht des DCFR: Perspektiven für eine Reform in Österreich und Europa?".JBl.

FABER, Wolfgang, Martin Lilja \& Günter KReUZbauer (2012). „Employing Argumentation Analysis in the Discussion of Optimal Rules for the Transfer of Movables". EPLJ.

FEenstRa, Robert (1949). Reclame en Revindicatie. Lieden: Ed. Tjeenk Willink.

Ferid, Murad und Hans J. SonnenberGER (1986). Das Französische Zivilrecht. $2^{\text {a }}$ ed. Heidelberg: Ed. C.F. Müller. Tomo 2.

Ferrari, Franco (1993). „Vom Abstraktionsprinzip und Konsensualprinzip zum Traditionsprinzip - $\mathrm{Zu}$ den Möglichkeiten der Rechtsangleichung im Mobiliarsachenrecht“. $Z E u P$ vol. 1.

Feser, Edward (2009). Aquinas. Washington DC: Ed. Oneworld Publications.

Flume, Werner (1990). Rechtsakt und Rechtsverhältnis: römische Jurisprudenz und modernrechtliches Denken. Paderborn: Ed. F. Schöningh.

Fuume, Werner (1992). Allgemeiner Teil des Bürgerlichen Rechts: Zweiter Band Das Rechtsgeschäft. $4^{\mathrm{a}}$ ed. Wien/New York: Ed. Springer. .

Forschner, Benedikt (2012). „The Sceptical Mind - Towards a New European Ius Commune?".JEHL. Vol. 3.

Giaro, Tomasz (1994). „Europäische Privatrechtsgeschichte: Werkzeug der Rechtsvereinheitlichung und Produkt der Kategorienvermengung“. Ius commune. Vol. 21. 
GLÜCK, Christian Friedrich (1807). Ausführliche Erläuterungen der Pandekten nach Hellfeld. Erlangen: Ed. Johann Jacob Palm. Tomo 8.

Goldt, Arnd (2002). Sachenrechtliche Frage des grenzüberschreitenden Versendungskaufs aus international-privatrechtlicher Sicht. Berlin: Ed. Duncker und Humblot.

Goode, Royston Miles (2004). Commercial law. $3^{\mathrm{a}}$ ed. London: Ed. LexisNexis.

Grigoleit, Hans Cristoph (1999). „Abstraktion und Willensmängel - Die Anfechtbarkeit des Verfügungsgeschäfts“. AcP. vol. 199.

Grossi, Paolo (ed.) (1973). La seconda scolastica nella formazione del diritto privato moderno. Milano: Ed. Giuffrè.

Grotius, Hugo (1735). De iure belli ac pacis. Ed. Amsterdam.

262 Gsell, Beate (2014). „Zivilrechtsanwendung im Europäischen Mehrebenensystem“. AcP. Vol. 214.

GuZMán Brito, Alejandro (1977). La fijación del derecho. Valparaíso: Ediciones Universitarias de Valparaíso.

GuZmán Brito, Alejandro (2011). Codificación del derecho civil e interpretación de las leyes. Madrid: Ed. Iustel.

HäcKER, Birke (2011). „Das Trennungsund Abstraktionsprinzip im englischen Recht - dargestellt anhand der Übereignung“. ZEuP. Vol. 19.

HARKE, Jan Dirk (2012). „Kausalprinzip, Abstraktion und gutgläubiger Erwerb“. GPR.

HÅSTAD, Torgny (2009). , Derivative acquisition of ownership of goods“. ERPL.

Heck, Philipp (1930). Grundriß des Sachenrechts. Tübingen: Ed. Mohr Siebeck.
Henninger, Thomas (2009). Europäisches Privatrecht und Methode. Tübingen: Ed. Mohr Siebeck.

HöFFE, Ottfried (2008). Kleine Geschichte der Philosophie. $2^{\mathrm{a}}$ ed. München: Ed. C. H. Beck.

Hofmann, Franz (1873). Die Lehre vom titulus und modus adquirendi, und von der iusta causa traditionis. Wien: Ed. Manz.

Honoré, Tony (1983). Sale and Transfer of Property - The compilers'point of view, in Peter Stein (ed.). Studies in Memory of J.A.C. Thomas. London: Ed. Sweet \& Maxwell.

Huber, Ulrich (2003). „Savignys Lehre von der Auslegung der Gesetze in heutiger Sicht". JZ.

Huber, Ulrich (2007). Savigny und das sachenrechtliche Abstraktionsprinzip, en Heldrich, Andreas (ed.) Festschrift Claus-Wilhelm Canaris. München: Ed. C.H. Beck.

Jauernig, Othmar (2014). Bürgerliches Gestzbuch. $15^{\mathrm{a}}$ edi. München:Ed.C.H. Beck.

JaKOBS, Horst Heinrich (1983). Wissenschaft und Gesetzgebung im bürgerlichen Recht: nach der Rechtsquellenlehre des 19. Jahrhunderts. Paderborn: Ed. Schöningh.

Jаковs, Horst Heinrich (2002). „Gibt es den dinglichen Vertrag?““. ZRG RA. Vol. 119.

Jansen, Nils (2012). Irrtumsanfechtung im Vorschlag für ein Gemeinsames Europäisches Kaufrecht, in Hans SCHULTENÖLKE, Frederyk ZolL, Nils Jansen, und Reiner Schulze (eds.). Der Entwurf für ein optionales europäisches Kaufrecht. Tübingen: Ed. Sellier.

Jansen, Nils und Reinhard ZimmerMANN (2010). „Vertragsschluss und Irrtum im europäischen Vertrags- 
recht - Textstufen transnationaler Modellregelungen“. AcP. Vol. 210.

JHERInG, Rudolf von (1888). Geist des römischen Rechts auf den verschiedenen Stufen seiner Entwicklung. Leipzig: Ed. Breitkopf und Härtel. Vol. III/2.

Kaser, Max (1961). „Zur ,iusta causa traditionis“". BIDR. Vol. 64.

KASER, Max (1962). Compraventa y transmisión de la propiedad en el Derecho romano y en la dogmática moderna. Valladolid: Ed. Publicaciones de los Seminarios de la Facultad de Derecho de la Universidad de Valladolid.

KASER, Max (1971). Römisches Privatrecht. $2^{\mathrm{a}}$ ed. München: Ed. Beck. Vol. I.

Kaser, Max und Rolf KNüTEL (2013). Römisches Privatrecht: ein Studienbuch. $20^{\mathrm{a}}$ ed. München: Ed. Beck.

KEGEL, Gerhard (1977). Verpflichtung und Verfügung: Sollen Verfügungen abstrakt oder kausal sein? Festchrift Frederick Alexander Mann. München: C.H. Beck.

KNÜTEL, Rolf (1991). "Compraventa y transferencia de la propiedad en el derecho alemán”, en Letizia VACCA (ed.). Vendita e trasferimento della proprietà nella prospettiva storico-comparatistica. Milano: Ed. Giuffrè.

Kramer, Ernst August (2009). "Ein Blick auf neue europäische und außereuropäische Zivilgesetzbücher und Entwürfe zu solchen",in Wolfgang WiEgand. Festschrift Eugen Bucher. Zurich: Ed. Stämpfli.

KrAMER, Ernst August (2012). Münchener Kommentar zum BGB. 6 $6^{\text {a }}$ ed. München: Ed. C.H. Beck.

KrAMER, Ernst August et al. (2013).Juristische Methodenlehre. $4^{\mathrm{a}}$ ed. München: Ed. C.H. Beck .
Kropholler, Jan (1975). Internationales Einheitsrecht - Allgemeine Lehren. Tübingen: Ed. Mohr Siebeck.

Kunkel, Wolfgang und Theo MAYerMaly (1987). Römisches Recht. $4^{\mathrm{a}}$ ed. Wien/New York: Springer.

LANDAU, Peter (1973). „Hegels Begründung des Vertragsrechts“. ARSP. Vol. 69.

LARENZ, Karl (1986). Schuldrecht Allgemeiner Teil. $13^{\mathrm{a}}$ ed. München: Ed. C.H. Beck.

LARENZ, Karl und Claus-Wilhelm CANARIS (1994). Lehrbuch des Schuldrechts. $13^{\mathrm{a}}$ ed. München: Ed. C.H. Beck. Vol. II/2.

Larenz, Karl und Claus-Wilhelm CANARIS (2005). Methodenlehre der Rechtswissenschaft. $3^{\mathrm{a}}$ ed. Wien/New York: Ed. Springer.

LAUSBerg, Heinrich (2008). Handbuch der literarischen Rhetorik. $4^{\mathrm{a}}$ ed. Stuttgart: Ed. Steiner.

LoOschelders, Dirk (2012). „Das allgemeine Vertragsrecht des Common European Sales Law“. AcP. Vol. 212.

LORENZ, Stephan (2012). „Das Kaufrecht und die damit verbundenen Dienstverträge im Common European Sales Law“. AcP. Vol. 212.

LuIG, Klaus (1985). Übergabe und Übereignung der verkauften Sache nach römischem und gemeinem Recht, in Hans Ankum. Festschrift Robert Feenstra. Heidelberg: Ed. Schweizer Universitätsverlag.

Lurger, Brigitta (2008). "Introduction to the project 'transfer of movables': organisational framework, basic issues and goals", in Brigitta LURGER \& Wolfgang FABER (ed.). Rules for the transfer of movables. Tübingen: Ed. Sellier. 
Lurger, Brigitta \& Wolfgang FABer, (2011). Principles of European Law Acquisition and Loss of Ownership of Goods. Berlin: Ed. Walter de Gruyter.

Malaurie, Laurent et Philippe Aynès, (2012). Les contrats spéciaux. $6^{\mathrm{a}} \mathrm{ed}$. París: Ed. LGDJ.

Mansel, Heinz-Peter (2014). en Othmar JAUERNIG, Bürgerliches Gesetzbuch. 15 ed. München: Ed. C.H. Beck.

Marín Castán, Francisco (2000). "Art. 609”, en Ignacio Sierra GIL DE LA Cuesta (ed.). Comentario del Código civil. Barcelona: Ed. Bosch.

Martens, Sebastian A.E. (2013). Methodenlehre des Unionsrechts. Tübingen: Ed. Mohr Siebeck.

Martinson, Claes (2008). "How Swedish Lawyers think about, ownership" and transfer of ownership“". Rules for the transfer of movables. Tübingen: Ed. Sellier.

Marx, Karl und Friedrich Engels, (1973). Werke (MEW), Institut für Marxismus-Leninismus beim Zentralkomitee der SED. Berlin: Ed. Dietz. Vol. 40

Mayer-Maly, Theo (1990). "Kauf und Eigentumsübergang im römischen Recht", in Letizia VACCA (ed.) Vendita e trasferimento della proprietà nella prospettiva storico-comparatistica. Milano: Ed. Giuffrè.

Mayer-Maly, Theo (1971). „Die Wiederkehr der Rechtsfiguren".JZ.

Meder, Stephan (2004). Mißverstehen und Verstehen: Savignys Grundlegung der juristischen Hermeneutik. Tübingen: Ed. Mohr Siebeck.

Michaels, Ralf (2002). Sachzuordnung durch Kaufvertrag: Traditionsprinzip, Konsensprinzip, ius ad rem in Geschich- te, Theorie und geltendem Recht. Berlin: Ed. Duncker \& Humblot.

Michaels, Ralf (2006). "The functional method of comparative law", in Mathias REIMANN \& Reinhard ZimMERMANN (ed.). Oxford Handbook of comparative law. Oxford: Ed. Oxford University Press.

Mugdan, Benno (1899). Die gesammten Materialien zum Bürgerlichen Gesetzbuch für das Deutsche Reich. Berlin: Ed. R. v. Decker. Vol. 3.

PatT, Walter (2007). Metaphysik bei Thomas von Aquin: eine Einführung. $2^{\mathrm{a}} \mathrm{ed}$. London: Ed. Turnshare Ltd.

Pelloso, Carlo (2012). „The concepts of 'bargain' and the (un-)bridgeable gulf between Common Law and Civil Law and some Observations on the Europeanization of the Law of Contracts". RGDR. Vol. 19.

Petronio, Ugo (1991). "Vendita, trasferimento della proprietà e vendita di cosa altrui nella formazione del Code civil e dell' Allgemeines Buergerliches Gesetzbuch", in Letizia VACCA (ed.) Vendita e trasferimento della proprietà nella prospettiva storico-comparatistica. Milano: Ed. Giuffrè.

Pfeiffer, Thomas (2012). Reiner ScHulZE (ed.) Common European Sales Law. München: C.H. Beck.

Picker, Eduard (2001). „Rechtsgeschichte und Rechtsdogmatik“. AcP. Vol. 201.

Potacs, Michael (2009). „Effet utile als Auslegungsgrundsatz". EuR.

Prisching, Margareth (2006). Gutgläubiger Erwerb an beweglichen Sachen im Rechtsvergleich. Gratz: Ed. Leykam.

Pufendorf, Samuel von (1795). De iure naturae et gentium. 
Pugliese, Giovanni (1997). "Compravendita e trasferimento della proprietà in diritto romano", en Letizia VACCA (ed.). Vendita e trasferimento della proprietà nella prospettiva storicocomparatistica. Milano: Ed. Giuffrè.

Rabel, Ernst (1936). Das Recht des Warenkaufs. Berlin: Ed. De Gruyter. Vol. 1

RABEL, Ernst (1957). „Observations sur l'utilité d'une unification du droit de la vente au point de vue des besoins du commerce international“. RabelsZ. Vol. 22.

RABEL, Ernst (1967). Gesammelte Aufsätze, Tübingen: Bearbeitung NorbertGLESER, Ed. Mohr Siebeck. Vol. 3.

RADBRuch, Gustav (1993). Rechtsphilosophi. $2^{\mathrm{a}}$ ed. Heidelberg: Ed. C.F. Müller.

RANIERI, Filippo (1977). Die Lehre der abstrakten Übereignung, in Helmut COING und Walter WilHELM (eds.). Wissenschaft und Kodifikation des Privatrechts im 19. Jahrhundert. Frankfurt: Ed. Klostermann. Tomo 2.

RANIERI, Filippo (2009). Europäisches Obligationenrecht. $3^{\mathrm{a}} \mathrm{ed}$. Wien/New York: Ed. Springer.

Rank-Berenschot, Eline (2011). Nieuwenhuis/Stolker/Valk, Burgerlijk Wetbook. $9^{\mathrm{a}}$ ed. Amsterdam: Kluwer.

REID, Kenneth (1996). The Law of Property in Scotland. London: Ed. Butterworths.

RÜFner, Thomas (2012). „Sieben Fragen zum EU-Kaufrecht - Oder: Was man heute schon über den Kommissionsvorschlag für ein Gemeinsames Kaufrecht wissen sollte“. ZJS.

Rummel, Peter (2000). Rummel, Kommentar zum Allgemeinen Bürgerlichen Gesetzbuch. $3^{\mathrm{a}}$ ed. Wien: Manz.
Saint-Alary Houin, Corinne (1991). "Le transfert de propriété depuis le code civil", in Letizia VACCA (ed.). Vendita e trasferimento della proprietà nella prospettiva storico-comparatistica. Milano: Ed. Giuffrè.

Salomons, Arthur F. (2009). „Fifteen Questions on the Rules Regarding the Acquisition of Movables in Book VIII Draft Common Frame of Reference“. ERPL. Vol. 17.

SAVigny, Friedrich Carl von (1840). System des heutigen römischen Rechts. Berlin: Ed. Veit \& Comp. Vol. 3.

Savigny, Friedrich Carl von (1840). Vom Beruf unserer Zeit für Gesetzgebung und Rechtswissenschaft. $3^{\mathrm{a}}$ ed. Tübingen: Ed.J.C.B. Mohr.

SAVigny, Friedrich Carl von (1853). Das Obligationenrecht als Theil des heutigen Römischen Rechts. Berlin: Ed. Veit \& Comp. Vol. 3.

SchermaIER, Martin Josef (2003). Schmoeckel/Rückert/Zimmermann, HistorischKritischer Kommentar zum BGB.Tübingen: Ed. Mohr Siebeck. Vol. 1.

Schiavone, Aldo (2005). Ius. L'invenzione del diritto in Occidente. Milano: Ed. G. Einaudi.

Schlechtriem, Peter (2000). Restitution und Bereicherungsausgleich in Europa. Tübingen: Ed. Mohr Siebeck. Vol. 1.

Schlechtriem Peter und Ingeborg SCHWENZER (2013). Kommentar zum Einheitlichen UN-Kaufrecht. $6^{\mathrm{a}}$ ed. München: (CISG). Ed. C.H. Beck.

Schmiduin, Bruno (1990). "Il trasferimento di proprietà nel contratto di vendita nel diritto svizzero", in Letizia VACCA (ed.). Vendita e trasferimento della proprietà nella prospettiva storicocomparatistica. Milano: Ed. Giuffrè. 
Schmidun, Bruno (1999). "Die beiden Vertragsmodelle des europäischen Zivilrechts: Das naturrechtliche Modell der Versprechensübertragung und das pandektistische Modell der vereinigten Willenserklärungen", in Reinhard ZimmermanN (ed.). Rechts geschichte und Privatrechtsdogmatik, Heidelberg: Ed. C.F. Müller.

Schmidt-Kessel, Martin (2005). "Sachenrecht im Gemeinschaftsprivatrecht -eine Skizze", in Wojciech DAJCZAK und Hans-Georg Knothe (eds.). Deutsches Sachenrecht in polnischer Gerichtspraxis-Das BGB-Sachenrecht in der polnischen höchstrichterlichen Rechtsprechung in den Jahren 1920-1939: Tradition und Europäisches Perspektive, Berlin: Ed. Duncker \& Humblot.

SchröDER, Jan (2001). Recht als Wissenschaft: Geschichte der juristischen Methode vom Humanismus bis zur historischen Schule (1500-1850). München: Ed. C.H. Beck.

Schulte, Hans (1977). „Zur Möglichkeit stillschweigenden Eigentumsvorbehalts". $B B$.

Schulz, Fritz (1951). Classical Roman Law. Oxford: Ed. Oxford University Press.

Schwander, Ivo (2011). Basler Kommentar zum Schweizerischen Privatrecht. $4^{\mathrm{a}}$ ed. Basel: Ed. Helbing und Lichtenhahn.

Seelmann, Kurt (1997). Theologie undJurisprudenz an der Schwelle zur Moderne - Die Geburt des neuzeitlichen Naturrechts in der iberischen Spätscholastik. Baden-Baden: Ed. Nomos.

SERICK, Rolf (1965). Eigentumsvorbehalt und Sicherungsübertragung. Heidelberg: Ed. Verlagsgesellschaft Recht und Wirtschaft. Vol. 1.
SPIElbüChler, Karl (2000). Rummel, Kommentar zum Allgemeinen Bürgerlichen Gesetzbuch. $3^{\mathrm{a}}$ ed. Wien: Ed. Manz.

STADLER, Astrid (1996). Gestaltungsfreiheit und Verkehrsschutz durch Abstraktion. Tübingen: Ed. Mohr Siebeck.

Stadler, Astrid (2014). Jauernig, Bürgerliches Gesetzbuch mit Allgemeinem Gleichbehandlungsgesetz. 15 a ed. München: Ed. C.H. Beck.

StAGL, Jakob Fortunat (2007). "Die Ausgleichung von Vorteil und Nachteil als Inhalt klassischer aequitas", in Aldo Schiavone und Dario MaNTOVANI (eds.). Testi e problemi del giusnaturalismo romano. Pavía: Ed. Iuss Press.

Stagl, Jakob Fortunat (2007). „Die Rezeption der Lehre vom Rechtsgeschäft in Österreich durch Joseph Unger“. ZEuP. Vol. 15.

StaGL, Jakob Fortunat (2009). Favor dotis - Die Sonderstellung der Mitgift im System des römischen Rechts. Wien: Ed. Böhlau.

STAGL, Jakob Fortunat (2011). „Eine Flucht nach Rom - Der geistige Weg Ernst Rabels“. TR 79.

STAGL, Jakob Fortunat (2011). „Gutgläubiger Erwerb durch ,sofortige Ersitzung ${ }^{6}$ - Eine Neubestimmung der $\S \S$ 932 ss. BGB“. AcP. Vol. 211.

Stagl, Jakob Fortunat (2013). „Durch Rede zum Recht am Beispiel von Quint. decl. 360“, JEHL.

StAGL, Jakob Fortunat (2014). „Das ,testamentum militare' als ,ius singulare““. REHJ. Vol. 36.

Stagl, Jakob Fortunat (2014). „Der Glanz der Rhetorik und die Finsterkeit der Logik“. Fundamina. Vol. 20. 
STAGL, Jakob Fortunat (2015). „Der Eigentumsvorbehalt der Römer als Vorbehalt des Besitzes". ZRG RA. Vol. 132.

Strohal, Emil (1889). „Rechtsübertragung und Kausalgeschäft im Hinblick auf den Entwurf eines bürgerlichen Gesetzbuches für das Deutsche Reich“. JherJb. Vol. 27.

STÜRnER, Rolf (2014). „Die Zivilrechtswissenschaft und ihre Methodik $\mathrm{zu}$ rechtsanwendungsbezogen und zu wenig grundlagenorientiert?". AcP. Vol. 214.

TerRé, François et PhilippeSimler (2010). Droit civil/Les biens. $8^{\mathrm{a}}$ ed. Paris: Ed. LGDJ.

TomÁs Martínez, Gema(2014). "La transferencia del riesgo del precio y la transmisión de propiedad: hacia una definitiva desconexión conceptual y temporal en sede de armonización europea". $A D C$.

VEcCHIO, Giorgio del (1953-1954). Sur le prétendu caracterère "politique" du Droit, in Archives de Philosophie du Droit 2 (nouvelle serie).

Viaro, Silvia (2011). Corrispettività e adempimento nel sistema contrattuale romano. Milano: Ed. CEDAM.

VLIET, Lars van (2000). Transfer of movables in German, French, English and Dutch law. Amsterdam: Ed. Ars Aequi Libri.

VLIET, Lars van (2011). „Acquisition and Loss of ownership of Goods - Book VIII of the Draft Common Frame of Reference“. ZEuP. Vol. 19.

Von BAR, Christian \& Ulrich DrobNig, (2004). The Interaction of Contract Law and Tort and Property Law in Europe. Tübingen: Ed. Sellier.

Von Bar, Christian, Eric Clive \& Hans Schulte-Nölke (2009). Principles,
Definitions and Model Rules of European Private Law-Draft Common Frame of Reference (Outline edition). Tübingen: Ed. Sellier.

Wacke, Andreas (1974). Das Besitzkonstitut als Übergabesurrogat in Rechtsgeschichte und Rechtsdogmatik. Köhln: Ed. Hanstein.

Weber, Max (1904). 'Die „Objektivität“ sozialwissenschaftlicher und sozialpolitischer Erkenntnis, Erstdruck", in Archiv für Sozialwissenschaft und Sozialpolitik, Vol. 19. También en. Gesammelte Aufsätze zur Wissenschaftslehre. Tübingen: Ed. Mohr Siebeck. 1922.

Westermann, Harm Peter (2012). Münchener Kommentar zum BGB. München. C.H. Beck.

WIEACKER, Franz (1974). "Die vertragliche Obligation bei den Klassikern des Vernunftrechts". FS Hans Welzel. Heidelberg: Ed. C.F. Müller.

Windscheid, Bernhard und Theodor KIPP (1906). Lehrbuch des Pandektenrechts. $9^{\mathrm{a}}$ ed. . Frankfurt: Ed. Rütten und Loehning.

Zaccaria, Alessio, (2009). Di Cian e TraBUCCHI (a cura di). Commentario breve al Codice civile. $9^{\mathrm{a}}$ ed. Milano: Ed. CEDAM.

Zimmermann, Reinhard (1983). Das römisch-holländische Recht in Südafrika. Mainz: Ed. Wissenschaftliche Buchgesellschaft.

Zimmermann, Reinhard (1990). The Law of Obligations: Roman Foundations of the Civilian Tradition. Oxford: Ed. Oxford University Press.

Zimmermann, Reinhard (2001). „Europa und das römische Recht“. AcP.Vol. 202.

Zimmermann, Reinhard (2002). „Europa und das römische Recht". $A c P$ Vol. 202. 
Zimmermann, Reinhard, Nils Jansen (2009). ,Was ist und wozu der DCFR?“. NJW.

Zoll, Frederyk (2012). Schulze, Common European Sales Law. München: Ed. C.H. Beck.

Zwalve, Willem J. und Boudewijn SirKS, (2012). Grundzüge der europäischen Privatrechtsgeschichte: Einfuihrung und Sachenrecht. Wien: Ed. Böhlau.

\section{Documentos electrónicos}

Curve, Eric (2014). Proposal for a Common European Sales Law withdrawn, Post del 7. 1. 2014, en European Private Law News. Disponible en /www. epln.law.ed.ac.uk/2015/01/07/proposal-for-a-common-european-saleslaw-withdrawn/ [fecha de consulta:
European Law Institute (2014). Statement of the European Law Institute: Unlocking the Digital Single Market - An Instrument for 21st Century Europe. Disponible en www. europeanlawinstitute.eu/fileadmin/ user_upload/p_eli/Projects/Unlocking_the_Digital_Single_Market.pdf [fecha de consulta: 1 de junio de 2014].

FALCON, Andrea (2006), en Stanford Encyclopedia of Philosophy, s.v. Aristotle on Causality. Disponible en: http:// plato.stanford.edu/entries/aristotlecausality/[fecha de consulta: 4 de julio de 2014].

RöHL, Klaus F. (2013). "Grundlagen der Methodenlehre I", in Michael ANDERHEIDEn, Marietta Auer, Thomas Gutmann (ed.). Enzyklopädie zur Rechtsphilosophie. Disponible en www. enzyklopaedie-rechtsphilosophie. net [fecha de consulta: 11 de septiembre de 2014]. 